Discussion

Papers

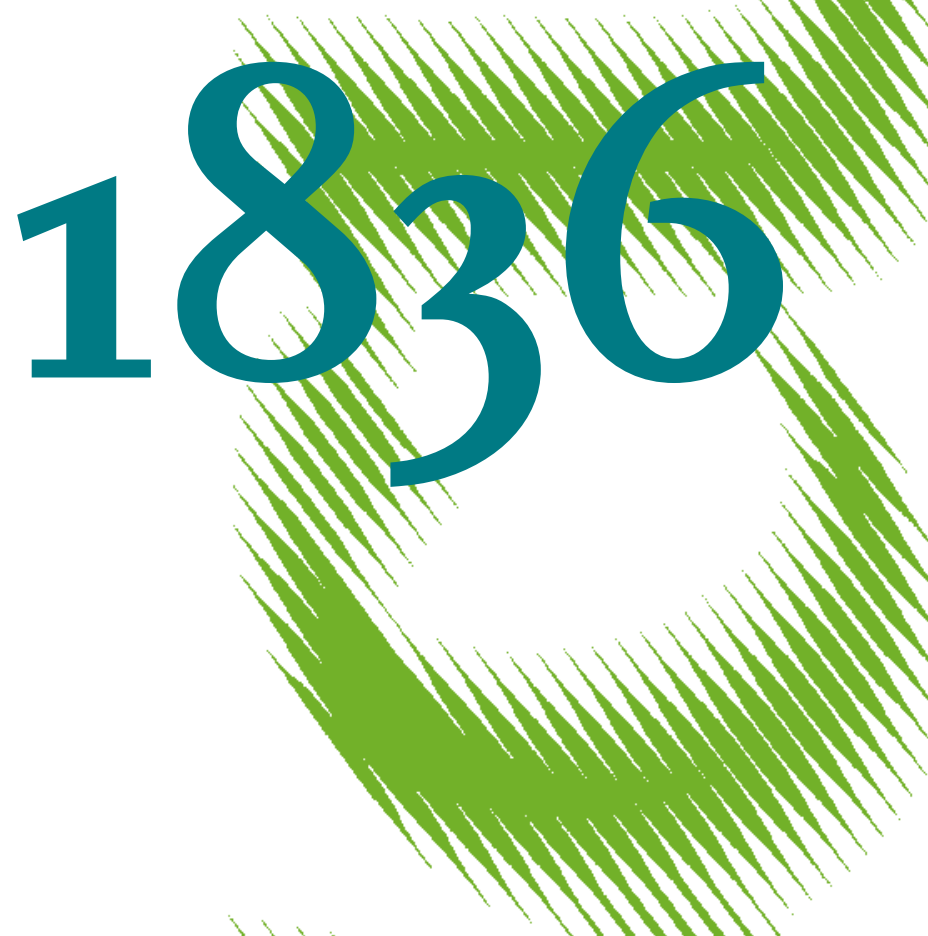

Merger Policy in Digital Markets: An EX-Post Assessment 
Opinions expressed in this paper are those of the author(s) and do not necessarily reflect views of the institute.

IMPRESSUM

(C) DIW Berlin, 2019

DIW Berlin

German Institute for Economic Research

Mohrenstr. 58

10117 Berlin

Tel. +49 (30) $89789-0$

Fax +49 (30) $89789-200$

http://www.diw.de

ISSN electronic edition 1619-4535

Papers can be downloaded free of charge from the DIW Berlin website:

http://www.diw.de/discussionpapers

Discussion Papers of DIW Berlin are indexed in RePEc and SSRN:

http://ideas.repec.org/s/diw/diwwpp.html

http://www.ssrn.com/link/DIW-Berlin-German-Inst-Econ-Res.html 


\title{
Merger Policy in Digital Markets: An Ex-Post Assessment*
}

\author{
Elena Argentesi, \\ University of Bologna \\ Paolo Buccirossi, \\ Lear \\ Emilio Calvano, \\ University of Bologna and Toulouse School of Economics \\ Tomaso Duso, ${ }^{+}$ \\ Deutsches Institut für Wirtschaftsforschung (DIW Berlin), TU Berlin, CEPR, and CESifo \\ Alessia Marrazzo \\ Lear and University of Bologna \\ Salvatore Nava \\ Lear
}

\begin{abstract}
This paper presents a broad retrospective evaluation of mergers and merger decisions in the digital sector. We first discuss the most crucial features of digital markets such as network effects, multi-sidedness, big data, and rapid innovation that create important challenges for competition policy. We show that these features have been key determinants of the theories of harm in major merger cases in the past few years. We then analyse the characteristics of almost 300 acquisitions carried out by three major digital companies -Amazon, Facebook, and Google between 2008 and 2018. We cluster target companies on their area of economic activity and show that they span a wide range of economic sectors. In most cases, their products and services appear to be complementary to those supplied by the acquirers. Moreover, target companies seem to be particularly young, being four-years-old or younger in nearly $60 \%$ of cases at the time of the acquisition. Finally, we examine two important merger cases, Facebook/Instagram and Google/Waze, providing a systematic assessment of the theories of harm considered by the UK competition authorities as well as evidence on the evolution of the market after the transactions were approved. We discuss whether the CAs performed complete and careful analyses to foresee the competitive consequences of the investigated mergers and whether a more effective merger control regime can be achieved within the current legal framework.
\end{abstract}

JEL codes: L4, K21

Keywords: Digital Markets, Mergers, Network Effects, Big Data, Platforms, Ex-post, Antitrust

\footnotetext{
* We thank the team at the Competition and Markets Authority for their assistance and guidance over the course of this study, including, in particular, Francesca Botti, Alistair Love, and Tom Kitchen. We are grateful to Elena Salomone, Anna Violini, and Daniele Michele Ferrari for their valuable research assistance. Tomaso Duso gratefully acknowledges support from the Berlin Center for Consumer Policies (BCCP).

${ }^{+}$Corresponding author. Deutsches Institut für Wirtschaftsforschung (DIW Berlin), Mohrenstr. 58, 10117 Berlin, Germany. Email: tduso@diw.de, Tel: +493089789520.
} 


\section{Introduction}

There is a mounting concern that competition authorities (CAs) are putting too much weight on the risk of an incorrect intervention (type I error) over the risk of an incorrect clearance (type II error) when assessing mergers in the digital sector, leading to increased concentration in digital markets. Indeed, the nature of competition in many digital markets may change the terms of the usual tradeoff between these errors. Network effects often make the structure of digital markets quite concentrated and barriers to entry rather high. Big data may contribute to such outcomes, to the extent that the data endowments enjoyed by incumbents provide a competitive advantage that makes it even more difficult to challenge them. The main mechanism left to discipline incumbents is that of competition for the market, i.e. that potential and actual entry mitigate the ability of incumbents to exert market power. This makes potential competitors even more valuable than they usually are in traditional markets, making type II errors particularly costly. In other words, certain features of digital markets may justify some changes in the way mergers in the sector are typically assessed.

Mergers may prevent the development of competitors in two main ways. Either directly, when the incumbent of a digital market acquires an entity that is an actual or potential competitor; or indirectly, when the incumbent acquires an entity that supplies a complementary product/service, thereby depriving its (actual or potential) competitors of the opportunity to do the same and improve their products to better challenge the incumbent.

To assess whether a merger will be detrimental to competition, CAs would need to predict the evolution of the market in the absence of the merger, i.e. the counterfactual. This is especially challenging when, as is often the case, targets are firms in the early stage of their development. In markets as dynamic as digital markets, young and innovative firms may grow and challenge the incumbent's position through independent decisions and/or investments made by venture capitalists and/or become the target of other entities in the industry that integrate it in their own operations. Hence, when defining the counterfactual to a merger, CAs may need to consider the ability of the target to develop on its own or by attracting outside resources, as well as the likelihood of an alternative buyer coming along.

In this paper, we discuss these issues by performing a broad ex-post evaluation of mergers and merger decisions in the digital sector. The paper is largely based on a study we conducted for the UK Competition and Markets Authority (henceforth "CMA") see Argentesi et al. (2019). In our work for the CMA, we were given access to a wealth of internal documents and submissions that, together with recent advances in the literature, allowed us to provide a more accurate ex-post assessment. $^{1}$

This paper contributes to a lively and cross-disciplinary debate on how to rethink competition policy for the digital era. Three recent and very influential reports set the stage ${ }^{2}$ highlighting a

\footnotetext{
${ }^{1}$ This paper does not rely on or disclose any of the confidential information we were given access to during our work for the CMA.
}

${ }^{2}$ Cremer et al. (2019) - European Commission, Scott Morton et al. (2019) - Stigler Center, Furman et al (2019) - UK Government. 
number of pressing competition policy issues and putting forward proposals to promote an international agenda to deal with them. The reports focus on broad issues that cut across markets and (oftentimes) industries deriving general guiding principles. They all call for legislative reforms, the possible set-up of a new regulator, and a more prominent role of ex-ante rules. On the contrary, in this paper we examine some important merger cases, providing systematic evidence where data were or became available. We also discuss whether CAs performed complete and careful analyses to foresee the competitive consequences of the investigated mergers and whether a more effective merger control regime can be achieved within the current legal framework.

The paper is structured as follows. In Section 2, we first review the relevant economic literature to identify some key characteristics of digital markets that might be important to evaluate the competitive effect of mergers in this sector. Based on these concepts, we then zoom in and examine a number of important merger cases undertaken by CAs - especially the European Commission and the CMA - to identify which theories of harm ("ToHs") have been typically pursued in the context of digital mergers.

In section 3, we then focus on a descriptive analysis of the almost 300 transactions carried out by key platforms, such as Google, Facebook, and Amazon, between 2008 and 2018. By grouping the targets of these mergers into clusters of economic activity, we seek to assess the strategy behind these mergers and, consequently, to understand whether they reveal any reason for concern.

In section 4, we then focus on two prominent mergers by these key players that attracted a significant interest: Facebook/Instagram and Google/Waze. In these case studies, we assess whether the decisions that the UK antitrust authorities arrived at was reasonable based on the evidence that was, or would reasonably have been, available at the time. This methodology assessment amounts to analyzing whether the ToHs pursued by the authorities were addressed correctly and whether there were any other ToHs that would have been reasonable to pursue. We then look at the market evolution following the mergers to ascertain whether the merger has led to a detrimental outcome. Specifically, we evaluate how the markets affected by the mergers have evolved since the merger and rely on qualitative evidence to investigate whether, and to what extent, the merger determined the outcome observed. For each case, we identify the relevant competitive parameters to assess market outcomes and assess their evolution since the merger date. Qualitative evidence coming from industry reports and interviews with merging and third parties are used to appropriately interpret and corroborate the quantitative analyses.

In section 5, we conclude the paper providing some recommendations for potential developments of merger control in digital market.

\section{Key concepts}

\subsection{Key concepts from the economic literature}

Certain features of digital markets create new challenges for competition policy. In this section, based on the literature survey discussed in Argentesi et al. (2019) as well as in Calvano and Polo 
(2019), we highlight the most crucial ones, which have been key determinants of the theories of harm in major merger cases in the past few years. Network effects, multi-sidedness, big data, and rapid innovation are recognized as important drivers of market structure in digital markets. All these features are often connected and related, thus constituting a particular challenge for policy makers, especially when enforcing merger policy.

Direct and indirect network effects are possibly the most central element of digital platform markets. ${ }^{3}$ When the value that consumers derive from a product depends on the number of other consumers who use the same product, as is often the case in the digital sector, markets may have a tendency to become highly concentrated, possibly tipping into monopoly. This implies that competition for the market, rather than in the market, is often the main mechanism to prevent incumbents in digital markets from exerting market power.

In this context, the most recent literature introduces and studies the notion of "incumbency advantage" (Biglaiser, Calvano and Cremer, 2019). It captures the idea that an installed base of consumers may prevent entrants from penetrating the market despite the latter being endowed with better quality products. Some early contributions refer to this as "excess inertia." "A key mitigating factor often cited in policy debates is multi-homing. The low (or nil) usage costs and switching costs that characterize digital markets make consumers more willing to try other products, thereby reducing the incumbency advantage. ${ }^{5}$

Another aspect of the incumbency advantage, put forward by the economic literature on innovation, is the incentive for incumbents to carry out pre-emptive buyouts; that is, buyouts of entrants with the goal of reducing potential future competition. This so called "entry for buyout" (Rasmusen, 1988) may also end up in the extreme situation of "killer acquisitions," i.e. situations where the acquirer closes down the activity of the acquired entity (e.g. Cunningham et al. 2018). In Section 3 , we analyze the pattern of acquisitions by some large digital platforms in order to shed light on this issue.

Further, a large number of digital products and services are offered free of charge to consumers and paid for with advertising revenues within so-called "markets for attention." Attention is a scarce resource typically monetized through advertising. Advertisers are willing to pay more for "exclusive" eyeballs than for those that can be reached through multiple means. This means that platforms (i.e. content providers) not only care about the size of their audiences but also about their composition, and that CAs should carefully assess how a merger between platforms can affect both.

\footnotetext{
${ }^{3}$ Firms active in digital markets typically leverage on technology to enable users to interact among themselves. For this reason, they are typically referred to as "platforms." Markets where the value that users on one side of the market assign to the platform depends on how many users on other sides of the market also patronize the platform are called "multi-sided" following a literature pioneered by Caillaud and Jullien (2003), Rochet and Tirole (2003, 2006), and Armstrong (2006).

${ }^{4}$ Early contributions focusing on the notion of switching costs include Farrell and Saloner (1986), Katz and Shapiro (1992), and Fudenberg and Tirole (2000). More recently, Halaburda, Jullien and Yehezkel (2018), Halaburda and Yehezkel (2016) and Biglaiser and Cremer (2018) relooked at this issue emphasizing the role of favourable expectations as a driver of the incumbency advantage. ${ }^{5}$ See Armstrong (2006) and Jeitschko and Tremblay (2018) for further discussion.

${ }^{6}$ Anderson and Coate (2005) offer an early contribution, while Ambrus et al. (2016) and Prat and Valletti (2019) offer newer ones.
} 
Indeed, recent academic contributions on the topic of online advertising have stressed that multihoming - which is consistently regarded as a factor mitigating the anticompetitive effects of mergers in markets with network effects - can become a source of market power when it is across the merging parties' products. This is because the subset of such multi-homing users becomes exclusive to the newly merged entity, thus increasing its market power (Prat and Valletti, 2019).

Finally, since the quintessential task of many digital platforms is that of making predictions of various sorts, the data used to make these predictions ("big data") is becoming increasingly relevant to shaping competition dynamics in digital markets. ${ }^{7}$ CAs and practitioners are voicing concerns that big data may be an insurmountable competitive advantage that incumbents naturally enjoy as a by-product of their operations, further increasing barriers to entry. Mergers may further enrich data endowments - and thus the competitive advantage - enjoyed by incumbents of digital markets.

\subsection{Main theories of harm in digital mergers}

Over the last decade, CAs have evaluated a number of mergers between digital companies. In our report for the UK Competition and Markets Authority (Argentesi et al., 2019), we review a subset of these decisions to understand which theories of harm (ToHs) are typically pursued in digital mergers. Our discussion shows that these ToHs are largely built upon the relevant economic features of digital markets summarized in Section 2.1.

The following discussion is organized around two main groups of ToHs. In particular, Section 2.2.1 considers unilateral effects ToHs usually associated with horizontal mergers, while section 2.2.2 discusses vertical ToHs, which typically arise when there exists some form of complementarity between the products of the merging parties, either because one is an input for the other or because they are consumed jointly.

\subsubsection{Horizontal ToHs}

\section{Loss of competition with network effects and multi-homing}

As discussed in Section 2.1, network effects are a pervasive feature of digital markets. The mere existence of network effects in a market does not a priori indicate that a merger in this market raises competitive concerns. Yet, concerns may follow if network effects allow the merged entity to foreclose competitors or make it more difficult for competing providers to expand their customer base, i.e. raising barriers to entry or expansion. For their potential to confer the merged entity a significant degree of market power, network effects are sometimes central to some ToHs considered by competition authorities in their assessment of digital mergers. Multi-homing, i.e. the practice by users of using different services from competing providers at the same time, is generally regarded as a factor potentially mitigating the adverse impact of network effects on competition.

\footnotetext{
${ }^{7}$ The literature on big data in economics is still extremely scarce. The few exceptions are empirical studies such as Lambrecht and Tucker (2015), Bajari et al. (2019), and Schaefer et al. (2018), as well as theory papers such as Rubinfeld and Gal (2017), Prufer and Schottmüller (2017) and DeCorniere and Taylor (2019).
} 
One decision in which network effects played an important role was the Microsoft/Skype case. ${ }^{8}$ Microsoft, which was active in the design, development and supply of computer software and related services, also operated two communications services: "Windows Live Messenger" ("WLM") for consumers and "Lync" for enterprises. Skype offered a software for communications over the Internet. The parties' services presented three main functionalities: instant messaging (IM), voice, and video calls. While the Commission did not conclude on whether the market should be fragmented by functionalities, the horizontal assessment focused on video calls since the transaction led to the creation of a market leader only with respect to this service.

The Commission considered that network effects represented a barrier to entry and expansion in this market, as suggested by respondents to its market investigation, so that the merged entity's ability to exert market power post-transaction could be strengthened. However, the Commission pointed to the fact that most users make voice and video calls with their "inner circle," usually comprising four to six people, making it easier for these small groups to switch to other providers and mitigating the anticompetitive potential of network effects.

Moreover, the Commission observed that users multi-home to a certain degree. In particular, the merging parties submitted evidence revealing that [20-30]\% of WLM users were also Skype users and that a significant number of Skype IM users were also connected to Yahoo! Messenger, WLM, and AIM, while also visiting Gmail and Facebook. Users' tendency to multi-home mitigated the network effects' potential to confer the merged entity market power, since having a large network did not automatically imply that users would give up using competing consumer communications services.

\section{Loss of competition in markets for attention}

Mergers involving companies in competition with one another for consumer attention may increase their ability to exert market power within fairly broad online advertising markets, even where the services they supplied to consumers were different and not substitutable to one another.

Competing to attract consumer attention does not necessarily imply that a company exploits this attention for monetisation purposes. In Facebook/WhatsApp, ${ }^{9}$ for instance, WhatsApp was neither selling advertising space nor selling user data. Yet, it did receive potentially valuable consumer attention. Thus, the Commission considered whether, post-transaction, the merged entity could analyse WhatsApp users' data and use them to introduce targeted advertising on WhatsApp. This could have enabled Facebook to reinforce its position in the online advertising market with respect to two different possible counterfactuals:

- one where WhatsApp would have stuck to its pre-merger "no ads" strategy. In this scenario, the abovementioned strategy would have allowed the merged entity to publish ads on two outlets, Facebook and WhatsApp, potentially increasing their effectiveness and, therefore, making the merged entity more attractive to advertisers than Facebook alone would have been absent the merger;

\footnotetext{
${ }^{8}$ European Commission Decision of 7 October 2011 in Case M.6281- Microsoft/Skype, section 2.

${ }^{9}$ European Commission Decision of 3 October 2014 in Case M.7217 - Facebook/WhatsApp, section 5.3.2.
} 
- one where WhatsApp would have started providing advertising space. In this scenario, the transaction would remove a competitive constraint, potentially giving rise to unilateral effects in the market for online advertising as absent the transaction Facebook would have faced competition from WhatsApp. In assessing this $\mathrm{ToH}$, the Commission noted that this strategy was possible in theory, though it would have required WhatsApp to change its privacy policy.

Nevertheless, departing from the pre-merger "no ads" product strategy might not be profitable for WhatsApp, as some users might decide to switch to other consumer communications apps. Furthermore, the Commission's investigation revealed that the vast majority of market participants believed that, post-transaction, there would still remain a sufficient number of alternative providers of advertising space competing with Facebook.

\section{Loss of potential competition}

Even when the merging parties did not significantly constrain one another at the time of the merger, CAs investigated whether they would be likely to do so in the future. This requires assessing the likelihood that one of the merging parties will grow into an effective competitive force and whether there would remain a sufficient number of other actual or potential competitors to maintain competitive pressure after the merger.

The Google/DoubleClick ${ }^{10}$ case provides a good example of this ToH. At the time of the merger, both Google and DoubleClick were active in the online advertising sector. Google was selling ad space on its search engine website Google.com only for search-based text ads; additionally, it provided ad intermediation services through its ad network (AdSense), selling both search and contextual text ads on the web pages of the publishers participating in the network; finally, it was offering a bundle encompassing ad space, intermediation services, and ad serving tools. Google was the leading provider of online advertising and, in particular, of search ad space in the EEA. DoubleClick offered a display ad serving technology and it held a leading position on both the advertiser and publisher side of the market. ${ }^{11}$ Thus, in its merger investigation, the European Commission assessed whether 1) DoubleClick could have become a provider of ad intermediation services and, by extension, could have entered the market for the provision of bundled online ad intermediation and ad serving tools; and 2) Google could have become a provider of display ad serving tools. Both moves would have made the merging parties direct competitors, rendering the merger potentially anti-competitive.

The Commission noted that DoubleClick had already planned to enter the market for ad intermediation services by developing an ad-exchange. The Commission went on to assess: 1) whether it was likely that DoubleClick would have evolved in an effective competitive force; and 2) whether there would have been an insufficient number of other competitors left to provide

\footnotetext{
${ }^{10}$ European Commission Decision of 11 March 2008 in Case M.4731 - Google/DoubleClick, section 7.2.2.

${ }^{11}$ Ad Serving describes the process of delivering ads to viewers. Once ad space has been sold, ad serving is the technology ensuring that the correct ad actually appears (i.e. is served) onto the publisher website space at the right place at the right time. When a user connects to a webpage that features advertising, a server typically identifies the user via unique identifiers hidden in the browser (cookies) then uses the information stored about that viewer to serve him a relevant ad.
} 
competitive pressure after the merger. In order to answer these questions, the Commission analysed in depth whether DoubleClick held unique advantages that could favour such a development.

The Commission identified three types of possible advantages. First, DoubleClick could have leveraged integration between its ad serving technology and its planned ad-exchange to become a player in the online intermediation market. However, the Commission noted that such a combination would not have been unique to DoubleClick, as the market had witnessed a trend towards vertical integration with other intermediation players also benefiting from proprietary adserving technologies. In addition, Microsoft and Yahoo!, besides being vertically integrated, also operated a sophisticated ad search business allowing them to offer a larger bundle also including the provision of search ads spaces. DoubleClick would have been unable to replicate such offer absent the merger with Google.

Second, DoubleClick could have leveraged its existing customer base as a key asset that would have allowed it to grow into an effective competitor to Google. However, the Commission first noted that the size of this customer base did not seem to be such that DoubleClick would enjoy a significant advantage relative to its future ad intermediation competitors. Moreover, the Commission noted that there would be difficulties for DoubleClick in converting customers of ad serving tools into exclusive intermediation clients as both publishers and advertisers, especially middle and large companies such as DoubleClick's customers, preferred to use a mix of outlets, i.e. to multi-home.

Third, DoubleClick could have leveraged information about consumer behaviour collected through ad serving services to supply an intermediation service that could not be matched by competitors who do not have access to such data. ${ }^{12}$ However, the Commission noted that contractual relations linking DoubleClick with publishers and advertisers severely limited DoubleClick's ability to use this data to deliver services to other advertisers or publishers. The Commission considered that it was unlikely that these contractual restrictions would be removed post transaction. First, DoubleClick probably lacked the ability to impose such changes to its customers, as the available evidence suggested its market power was insufficient. Second, the existence of an incentive to try to do so was also doubtful, since such a fundamental change was considered a factor that could have persuaded many customers to switch to some alternative provider. Finally, such a data endowment would not have been unique and could be replicated by competitors.

The Commission concluded that, while it could not be excluded that DoubleClick would have grown into an effective competitor in the market for ad intermediation services, it was likely that a sufficient number of other competitors would be left in the market exerting competitive pressure to the merged entity post-merger.

The Commission also considered a second ToH related to the possibility that, absent the merger, Google could have become an effective competitor in the provision of display ad serving tools. In fact, it was working on a new ad serving product that was in the early stages of development. Yet,

${ }^{12}$ Doubleclick gathers different kinds of users' information such as queries to a search engine, request for the user's name and email address, and GIF tags to track the users' movements through the client web site. 
the Commission found no evidence indicating that Google was likely to grow into an effective competitive force. Indeed, it had no significant experience with display advertising or the advanced metrics required by customers purchasing display advertising. Additionally, other potential entrants into ad serving, in particular ad agencies and web portals, were better placed in terms of customer relationships, as they also provided their customers with rich media ads. Indeed, the Commission noticed that recent entrants into the ad serving market included agents belonging to these two categories (among which Microsoft and Yahoo!). Thus, even if Google were to succeed in the development of its display ad serving technology, it would be just one of many competitors.

\section{Loss of innovation}

When a merger combines two important innovators or eliminates a firm with promising pipeline products, the transaction can lead to a significant impediment of effective competition. Evidence from digital markets is still almost non-existence. Yet, the 2017 Dow/Dupont decision, ${ }^{13}$ although it does not concern digital markets, may still provide useful insights as to how to assess mergers that threaten innovation and on the remedies that can be adopted to remove the related competitive concerns.

The Dow/Dupont decision formulated for the first time a loss of innovation ToH whereby the merger may affect the merging parties' incentives to innovate post-merger. The transaction involved two large suppliers of crop protection chemicals and would have created a market leader. The parties to the merger competed as vertically integrated developers and manufacturers of pesticides (herbicides, fungicides, and insecticides). Innovation is considered of particular importance for the crop protection industry, which is highly concentrated. Indeed, farmers value new products that are less toxic or more efficient against pests, which may become resistant to existing active ingredients over time. Thus, innovation is crucial for capturing sales from competitors and defending existing sales. For this reason, within the loss of innovation ToHs, this fundamental role of innovation is highlighted by the fact that firms are assumed not only to compete in relevant product markets, but also in "innovation spaces."

The Commission's concern was that the merger threatened innovation competition by removing the parties' incentives to pursue ongoing parallel innovation efforts: the Commission found, indeed, that the parties were competing in important innovation areas. Since innovating in this industry is a lengthy and costly process, the parties would have likely had the incentive to discontinue some of their pipeline products. Moreover, the merger could have hampered innovation by removing the parties' incentives to develop and bring to market new pesticides: the merged entity's overall incentive to undertake innovation was considered to be lower than the sum of its parts. The Commission found that the second effect was likely to be significantly larger than the first one.

Due to the innovation-related concerns, the Commission conditioned the clearance of the merger on the divestment of DuPont's global pesticides business, including its R\&D division. The hypothesis was that the buyer of this divestment package would be empowered to replace the

\footnotetext{
${ }^{13}$ European Commission Decision of 23 March 2017 in Case M.7932 - Dow/Dupont.
} 
competitive constraint exerted by DuPont such that the number of effective competitors in the innovation spaces where DuPont was active would remain unchanged. Including DuPont's R\&D organisation and pipeline products was meant to ensure the viability and competitiveness of the divested business in the long-run.

\subsubsection{Vertical ToHs}

\section{Foreclosure with network effects and multi-homing}

Network effects, given their potential to represent a barrier to entry or expansion, could increase the likelihood of foreclosure, exacerbating the anticompetitive effects of the merged entity's exclusionary strategies.

This ToH was considered in the Microsoft/LinkedIn ${ }^{14}$ decision. LinkedIn was the leader in the market for Professional Services Networks (PSN), whereas Microsoft held a strong position in the markets for OSs and productivity software for PCs. The Commission explored whether the merged entity could leverage its strong market position from the markets for OSs and productivity software for PCs to the market for PSN services, thereby reinforcing LinkedIn's competitive advantage in this market and foreclosing its competitors. The strategies that could be pursued by the merged entity were: the pre-installation of a LinkedIn application on Windows PCs; and the integration of LinkedIn features into Microsoft Office, while at the same time denying the same levels of integration to competing providers of PSN services, for instance through denial of access to Microsoft Application Programming Interfaces (APIs).

Both strategies were considered technically feasible and capable of foreclosing competing providers of PSN services; also, the Commission noted that the merged entity was likely to have the incentive to engage in such strategies, as also suggested by Microsoft's internal documents, which explicitly mentioned the opportunities related to implementing these strategies posttransaction.

The Commission then went on to assess the overall likely impact on competition of these practices: this is where network effects come into play. According to the Commission, network effects could make foreclosure of existing competing providers of PSN services more credible through the following mechanism: the more LinkedIn's user base would grow, the more additional users would be willing to join the network and less willing to join instead competing PSN service providers. The Commission envisaged that this trend could have continued up to the point that the market would "tip" in LinkedIn's favour.

Moreover, network effects could represent barriers to entry for potential competitors, thereby exacerbating the anticompetitive potential of these foreclosing practices. Indeed, the Commission considered that potential entry of new PSN service providers could have, in principle, mitigated the impact of network effects, but concluded that this was not the case.

Another factor considered by the Commission for its potential to mitigate network effects was multi-homing; yet, in this case, it was considered insufficient. Indeed, multi-homing is likely to be

$\overline{{ }^{14} \text { Commission Decision of } 6 \text { December }} 2016$ in Case M.8124 - Microsoft/LinkedIn, section 4.2.3. 
more limited in PSN services as compared to consumer communications services: actively engaging on PSN platforms requires time and effort as users need to create their profile and keep it updated, build their network and interact with new contacts. The Commission found through its market investigation that, pre-merger, although many users did have accounts on multiple PSNs, they actively used only one of them or, at least, they viewed one of them as their "main network." This is because here network effects result from consumers using the service. Furthermore, the merger might even make multi-homing decrease for its potential to strengthen LinkedIn's market position and the subsequent reduced incentive for users to invest the effort associated with actively using competing PSNs.

The Commission concluded that these practices, namely the pre-installation of a LinkedIn application on Windows PCs, and the integration of LinkedIn features into Office and denial of access to Microsoft APIs, were likely to foreclose LinkedIn's competitors and have a negative impact on competition. In order to remove these concerns arising from the transaction, the merging parties submitted two sets of commitments. One set of commitments was meant to address the concerns related to the possible pre-installation of a LinkedIn application on Windows PCs; another set of commitments aimed at removing the concerns related to the possible integration of LinkedIn features into Office and denial of access to Microsoft APIs.

\section{Big data as an essential input to compete}

The data a firm owns can enter its productive process in several ways and, depending on how this occurs, the creation of a larger or more diverse dataset resulting from a merger may give the merged entity a competitive advantage potentially capable of foreclosing rivals. In traditional merger control, foreclosure ToHs are formulated when the transaction combines products that are complementary with each other and, as a result of the transaction, the merging parties' rivals are refused access to an important input. As discussed in section 2.1, data represents an increasingly important asset for firms operating in digital markets. In these markets, foreclosure can result from the combination of two previously independent datasets. The data a firm owns can, indeed, enter its productive process in several ways and, based on how this occurs, the creation of a larger or more diverse dataset resulting from a merger may give the merged entity a competitive advantage. However, this potentially negative effect on competition does not result from the mere exertion of market power: rather, it is the result of efficiencies realized by the merging parties that place them ahead of its competitors. In a sense, the restriction to competition comes from the merged entity becoming better at what it does and providing more value to its customers.

Access to data was the main source of concern in relation to the Apple/Shazam transaction. ${ }^{15}$ Apple and Shazam were active in the digital music industry, albeit with different roles. Other than designing, manufacturing, and selling mobile devices and personal computers, as well as developing the operating systems installed on these devices, Apple operated Apple Music, one of the leading music streaming platforms. Shazam not just offered a leading music recognition app for mobile devices and personal computers, but was also active in the online advertising market.

\footnotetext{
${ }^{15}$ European Commission Decision of 6 September 2018 in Case M.8788 - Apple/Shazam, section 8.4.2.
} 
One of the channels through which it generated revenues was the licensing of music data and analytics services.

The Commission investigated two main ways in which data combination could lead to diminished competition.

First, the Commission explored whether the transaction would give Apple access to commercially sensitive information about competing music-streaming platforms, in particular Spotify, ${ }^{16}$ which could put them at a competitive disadvantage in the market for digital music streaming apps and lead to their foreclosure. Indeed, data collected by Shazam included information regarding the user's identity, about the presence of non-pre-installed digital music streaming apps on the mobile devices where Shazam was installed, and some additional pieces of information for those users who have connected their Shazam account with their Spotify account.

Shazam's customer information was considered commercially sensitive as it could help Apple improve the effectiveness of its customer acquisitions strategies by targeting its rivals' customers through advertising or marketing campaigns. The Commission went on to assess whether Apple would have the ability and incentive to use this information to pursue such a strategy and what the overall impact of the strategy on competition would have been.

As regards the ability, the Commission considered that, while from a purely technical point of view this strategy would have been feasible for Apple, there might exist legal or contractual limitations to the use of Shazam's customer information post-transaction. Shazam was able to access data about which apps were installed on a user's Android device because the Android Developer Guidelines allowed it, but this could change at any point in time and was beyond Apple's control.

Regarding the incentive, the Commission noted that Apple's submissions and internal documents stressed that marketing efforts target new subscribers rather than switchers. Moreover, Apple submitted that it planned to change Shazam's data collection practices to bring them in line with Apple's policy: this would have meant that Shazam would no longer collect information on other apps installed on the user's mobile device unless this was consented to by the app developer.

In any case, the Commission concluded that the overall impact of these practices on competition would have likely been limited. Indeed, it noted that the same customer information would have been available to many other players post-transaction; Facebook and Twitter, for instance, collected information on their users' interests. Apple could have relied upon alternative providers to pursue these targeting strategies also before the transaction.

The second way in which data combination could have affected competition is more in line with the big data debate. Indeed, the Commission considered whether the data collected by Shazam could have been used to improve existing functionalities, or to offer additional functionalities, on digital music streaming apps, thereby qualifying as an important input with respect to the provision of digital music streaming services. For instance, one such improvement could have been offering

${ }^{16}$ Spotify was, indeed, the market leader in the European Economic Area (EEA), while Apple Music had rapidly become the second largest provider of music streaming services in the EEA since its launch in 2015. 
better targeted music suggestions to users. If this was the case, denying access to these data to competing providers of digital music streaming services could have significantly impeded competition in this market generating an exclusionary effect. While the Commission considered that the merged entity was likely to have the ability and incentive to use Shazam's data for similar purposes, it also noted that these strategies were unlikely to result in the foreclosure of Apple Music's competitors, and, more generally, to have a significant negative impact on competition. This conclusion was reached based on evidence from the Commission's market investigation suggesting that the type of data collected by music recognition apps did not appear to be an important input. The Commission compared Shazam's data to other available datasets on users of digital music services based on the so-called "four V's": $:{ }^{17}$ the variety of data composing the dataset; the speed at which the data are collected (velocity); the size of the data set (volume); and the economic relevance (value). It concluded that Shazam's data was not more comprehensive than other datasets available in the market, it was generated at a lower speed and with lower per user engagement, and had never been considered a strategic asset by the merging parties. In conclusion, even if the merged entity were to deny Apple Music's rivals access to Shazam's data, the impact on their ability to compete would have likely been minimal.

\section{Overview of past transactions carried out by leading digital companies}

Companies active in digital markets are remarkably active in mergers and acquisitions ("M\&A"), constantly seeking out interesting start-ups and purchasing them. Such acquisitions may have a variety of purposes: for instance, they may be conducted to secure a technology to be incorporated into the acquirer's product; or to secure highly skilled staff and use their expertise to develop products. However, such acquisitions may also have the intention or effect to wipe out potential competitors, as discussed in section 2.1. Buying out firms at an early stage of their development may effectively prevent them from ever becoming a competitive threat, as the innovation that they were developing will not serve to displace incumbents but will rather be instrumental to maintaining their market leadership or will be discontinued altogether.

This may be especially problematic in digital markets. As discussed in section 2.1, the prevalence of network effects makes it such that often competition is for the market rather than in the market. Consequently, the threat exerted by smaller market players or potential entrants is essential to keep market power in check. If such threats can be easily dealt with through targeted acquisitions, they cease to discipline market behaviour and leave room to the exercise of market power. Moreover, most of this M\&A activity occurs below the radar of competition authorities, as the large majority of transactions carried out by digital companies do not meet the relevant thresholds for merger control. Indeed, merger control thresholds are often based on merging parties' turnover, which are

\footnotetext{
${ }^{17}$ These are four relevant big data metrics as suggested in "Competition Law and Data," issue May 10, 2016, as a joint report of the Bundeskartellamt the German National Competition Authority ("NCA") and the French Autorité de la Concurrence, available at http://www.autoritedelaconcurrence.fr/doc/reportcompetitionlawanddatafinal.pdf.
} 
rarely met when targets are start-ups that in some instances are still trying to figure out a viable path to monetization. ${ }^{18}$

For the reasons outlined above, it is interesting to analyse the characteristics of M\&A activity carried out by major digital companies to understand whether they reveal any reason for concern. Our analysis covers all the publicly disclosed acquisitions carried out by Amazon, Facebook, and Google between 2008 and 2018, listed in the Appendix. Over this period, Google has acquired 168 companies, Facebook has acquired 71 companies and Amazon has acquired 60 companies, i.e. around 15,6 , and 5 transactions per year on average.

Targets are then grouped into clusters that convey their area of economic activity based on the Crunchbase database. ${ }^{19}$ Table 1 shows the clusters defined for the analysis, along with the number of transactions falling into each cluster. Figure 1 shows the distribution of transactions across clusters for each of Amazon, Facebook, and Google, excluding the Other cluster. Google has been remarkably more active than Amazon and Facebook, having bought out more companies than the other two in each of the clusters. Figure 1 also suggests a relatively strong focus by Amazon and Facebook on Physical goods and services and Communication apps and tools respectively, whereas Google's acquisitions are more evenly spread out across clusters.

\footnotetext{
${ }^{18}$ It is worth noting that different jurisdictions face different rules that might be more or less able to address such issues. For instance, the UK system differs from other systems because of its share of supply test, which is satisfied when the merger creates or enhances a 25 per cent share of supply or purchases of any goods or services in the UK. This test is not based on market share and allows wider discretion and more flexibility in describing the goods or services.

${ }^{19}$ Crunchbase is a platform for finding business information about private and public companies (https://www.crunchbase.com/)
} 
Table 1: Clusters for analysis of past acquisitions by Amazon, Facebook and Google

\begin{tabular}{|c|c|c|}
\hline Cluster & Description & Number \\
\hline $\begin{array}{l}\text { Communication apps and } \\
\text { tools }\end{array}$ & $\begin{array}{l}\text { Companies active in the supply of platforms that create or simplify } \\
\text { ways of interaction between individuals and/or within organizations. } \\
\text { Such ways of interaction include direct communication, such as } \\
\text { messaging and emailing, and sharing of content and personal } \\
\text { information }\end{array}$ & 50 \\
\hline Tools for developers & $\begin{array}{l}\text { Companies that provide tools and solutions for software developers to } \\
\text { create and optimize their digital products. This excludes products and } \\
\text { services supplied to final consumers }\end{array}$ & 40 \\
\hline $\begin{array}{l}\text { Physical goods and } \\
\text { services }\end{array}$ & $\begin{array}{l}\text { Companies that manufacture, distribute or sell physical goods of any } \\
\text { kind or facilitate through services and software such activities, } \\
\text { including price comparison websites, marketplaces and online retailers }\end{array}$ & 51 \\
\hline Digital content & $\begin{array}{l}\text { Companies that deliver, create or facilitate the fruition of digital } \\
\text { content such as movies, games, digital text and other digital media }\end{array}$ & 21 \\
\hline $\begin{array}{l}\text { Remote storage and file } \\
\text { transfer }\end{array}$ & $\begin{array}{l}\text { Companies that provide file storage, cloud, file sharing and related } \\
\text { services }\end{array}$ & 16 \\
\hline $\begin{array}{l}\text { Advertising tools and } \\
\text { platforms }\end{array}$ & $\begin{array}{l}\text { Companies active in the advertising industry as provider of advertising } \\
\text { content, advertising platforms or active as intermediaries between } \\
\text { advertisers and consumers or advertisers and suppliers }\end{array}$ & 17 \\
\hline $\begin{array}{l}\text { Artificial intelligence, data } \\
\text { science and analytics }\end{array}$ & $\begin{array}{l}\text { Companies active in the creation, distribution or enhancement of self- } \\
\text { learning software, image, speech or text recognition software, virtual } \\
\text { assistants, analytics and machine learning services for big data }\end{array}$ & 43 \\
\hline $\begin{array}{l}\text { Home, wellbeing and other } \\
\text { personal needs }\end{array}$ & $\begin{array}{l}\text { Companies active in the provision of software and applications } \\
\text { designed to simplify and/or improve experience for different aspects } \\
\text { of daily life such as: transportation, health, learning, entertainment, } \\
\text { wellbeing and home automation }\end{array}$ & 25 \\
\hline Other & & 36 \\
\hline Total & & 299 \\
\hline
\end{tabular}

Source: Lear based on Crunchbase data 


\section{Figure 1: Distribution of past acquisitions by cluster}

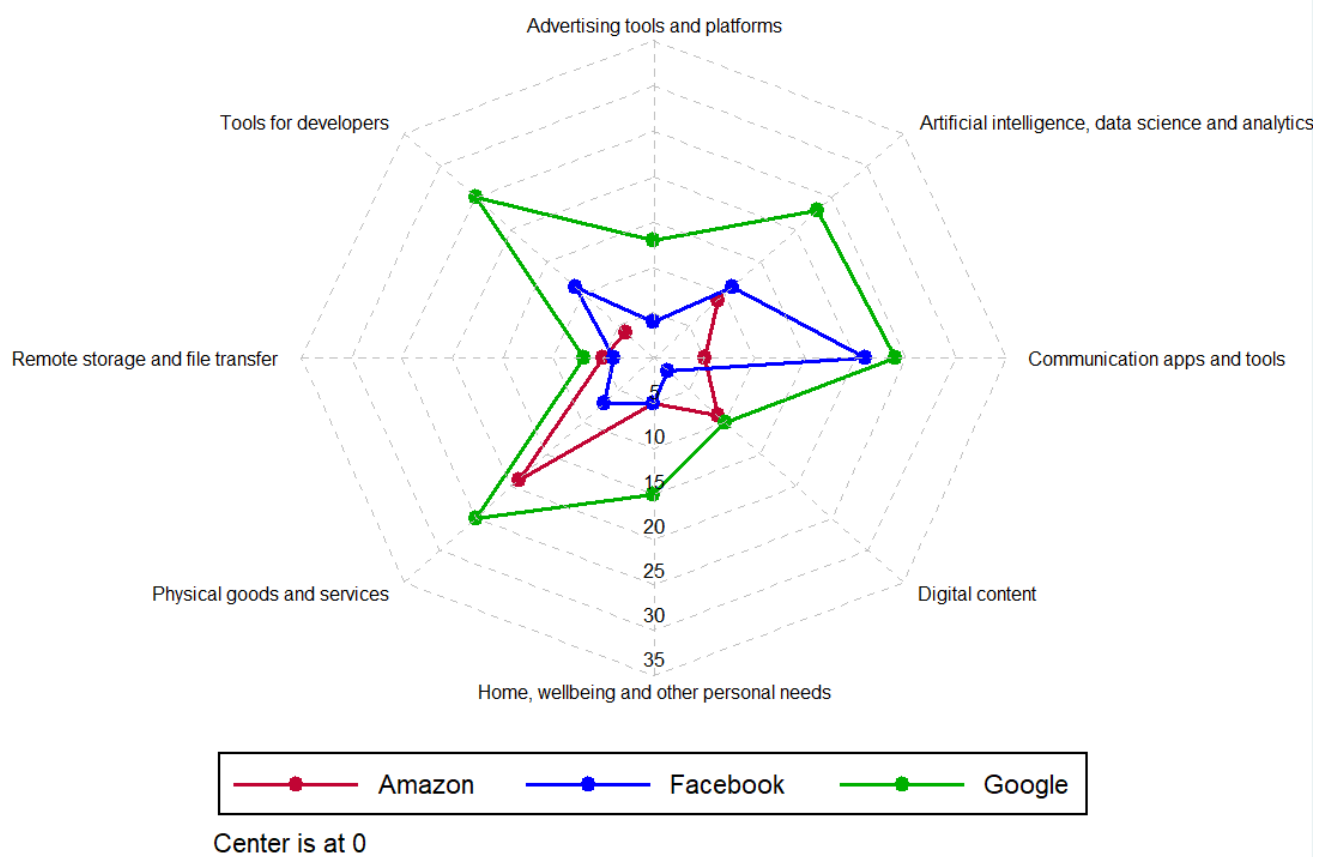

Source: authors based on Crunchbase data

Our main finding is that acquisitions target companies spanning a wide range of economic sectors and whose products and services appear to be complementary to those supplied by the acquirers. This highlights the complexity of the business models pursued by digital companies, as several activities seem to enter into their productive process. Transactions that can be characterized as more horizontal in nature would seem to be the minority.

Moreover, Amazon, Google, and Facebook have all invested in companies that have helped them with advanced data analytics techniques (machine learning, artificial intelligence, analytics and big data). This is consistent with the fact that these companies rely heavily on predictions to provide their services, as discussed in Section 2.1. For instance, Amazon uses them to manage its inventory based on expected demand; Facebook to propose targeted content and ads to its users; Google to improve its search algorithms and target ads more accurately. If this is the case, then these mergers may be efficiency-enhancing as they enable incumbents to become better at making such predictions. On the other hand, the improvement of prediction algorithms through external growth, complemented with the increasing collection of big data containing personalized information and with pervasive network effects, might help these firms to cement their dominant position in the market by creating unsurmountable barrier to enter for potential competitors.

Figures 2, 3, and 4 show how the number of acquisitions and their distribution across clusters has evolved over time, for each of the three companies. 
Figure 2: Number of acquisitions by Amazon over time

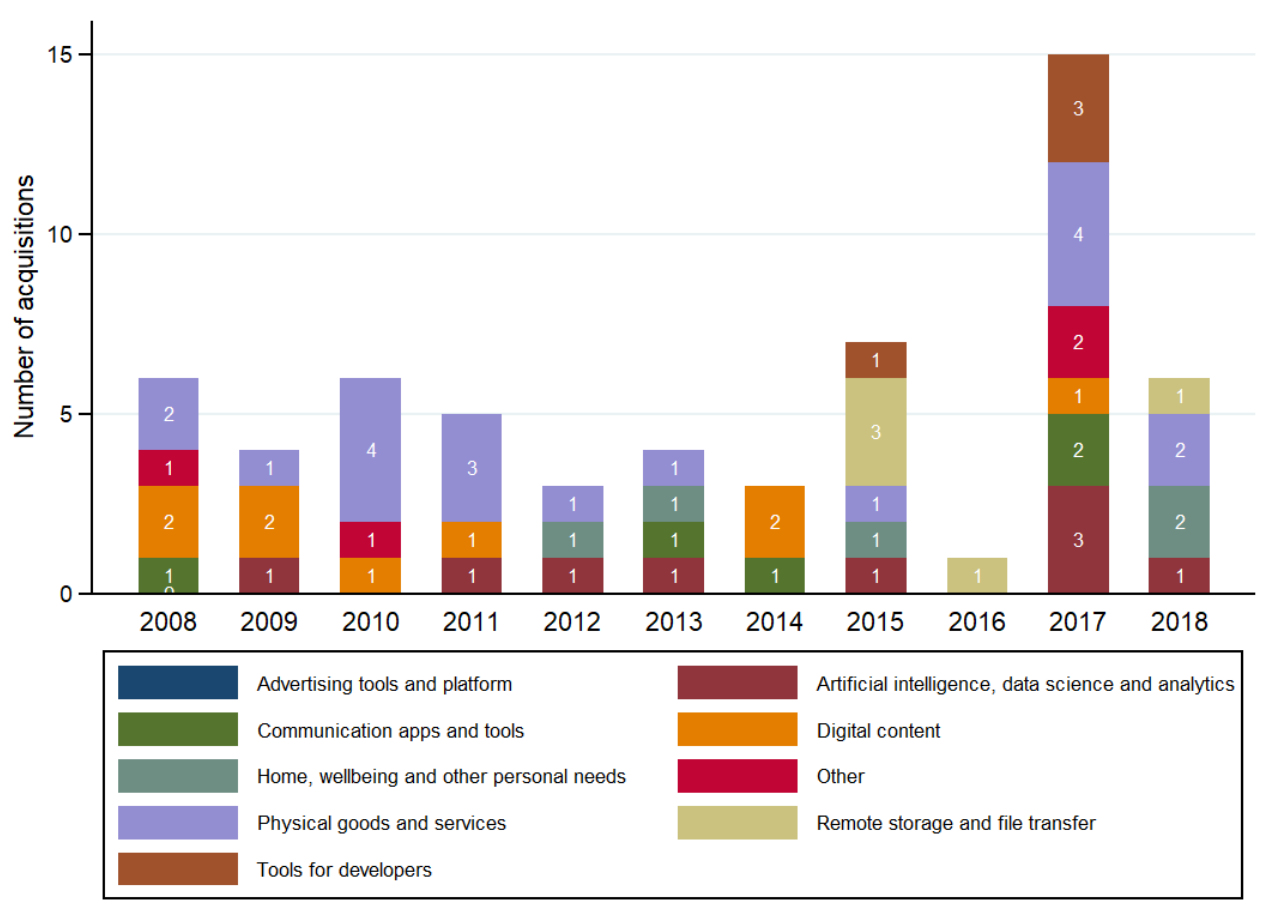

Source: authors based on Crunchbase data

As we can see from Figure 2, Amazon's acquisitions are clustered in the latter part of the period, with a peak in 2017. Between 2008 and 2013, Amazon completed several acquisitions in the Physical goods cluster; most of these were acquisitions of retail operators such as Buy VIP in 2010 and LoveFilm and The Book Depository in 2011. Starting in 2015, Amazon acquired companies in the Remote storage and file transfer cluster, perhaps with a view to bolster its own operations in this sector, where Amazon is active with Amazon Web Services. Other notable acquisitions by Amazon include Whole Foods Market, a supermarket chain, acquired in 2017 for 13.7 billion and Zappos, an online shoes retailer acquired in 2009 for 1.2 billion. 
Figure 3: Number of acquisitions by Facebook over time

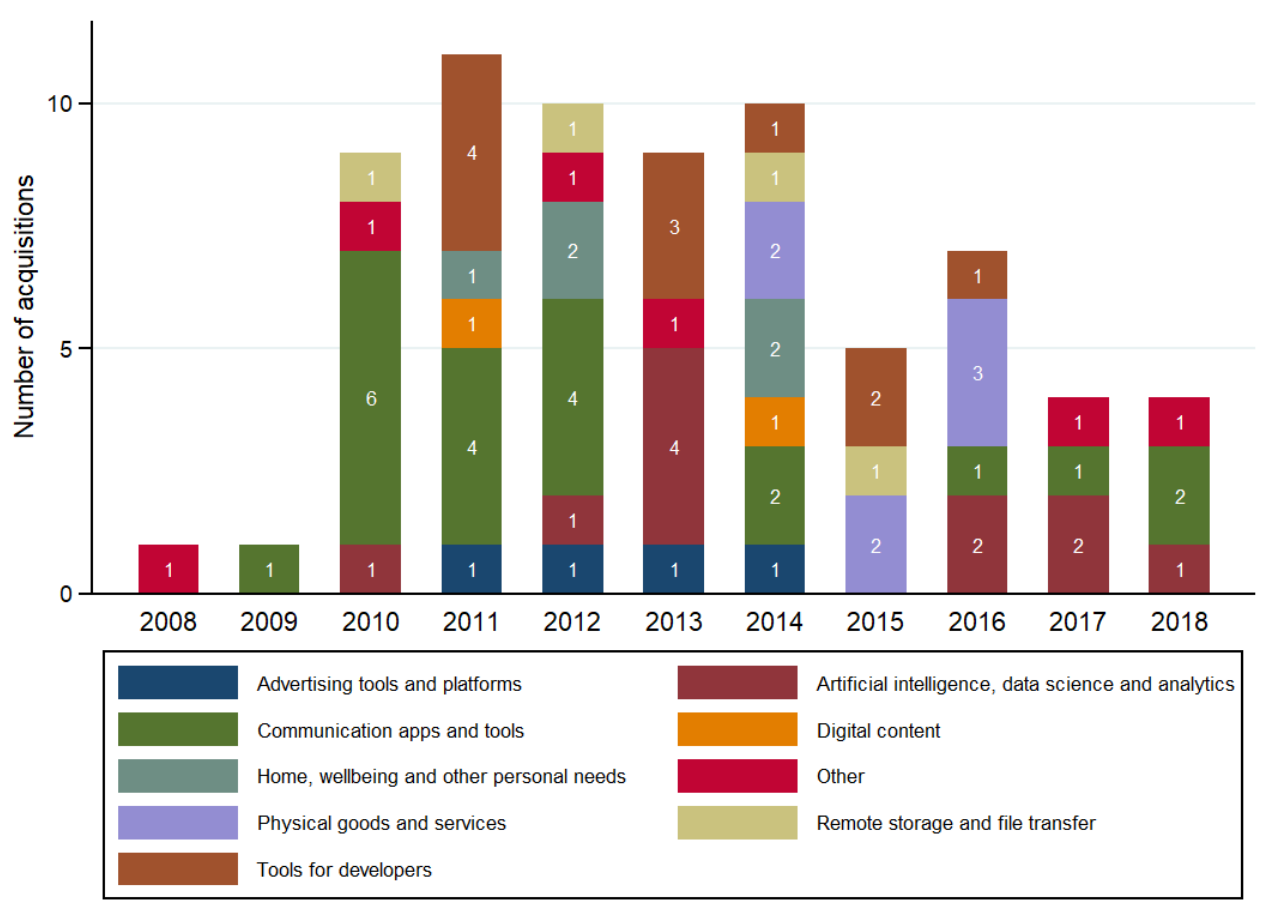

Source: authors based on Crunchbase data

Figure 3 shows that Facebook was remarkably active in M\&As between 2010 and 2016. Between 2009 and 2012, Facebook expanded its presence in the Communication apps and tools cluster with the notable acquisitions of the messaging app Beluga (2011), later transformed into Facebook Messenger, and Instagram (2012). From 2014 to 2016, Facebook invested in companies related to virtual reality technologies such as Oculus (2014) and Surreal Vision (2015). 
Figure 4: Number of acquisitions by Google over time

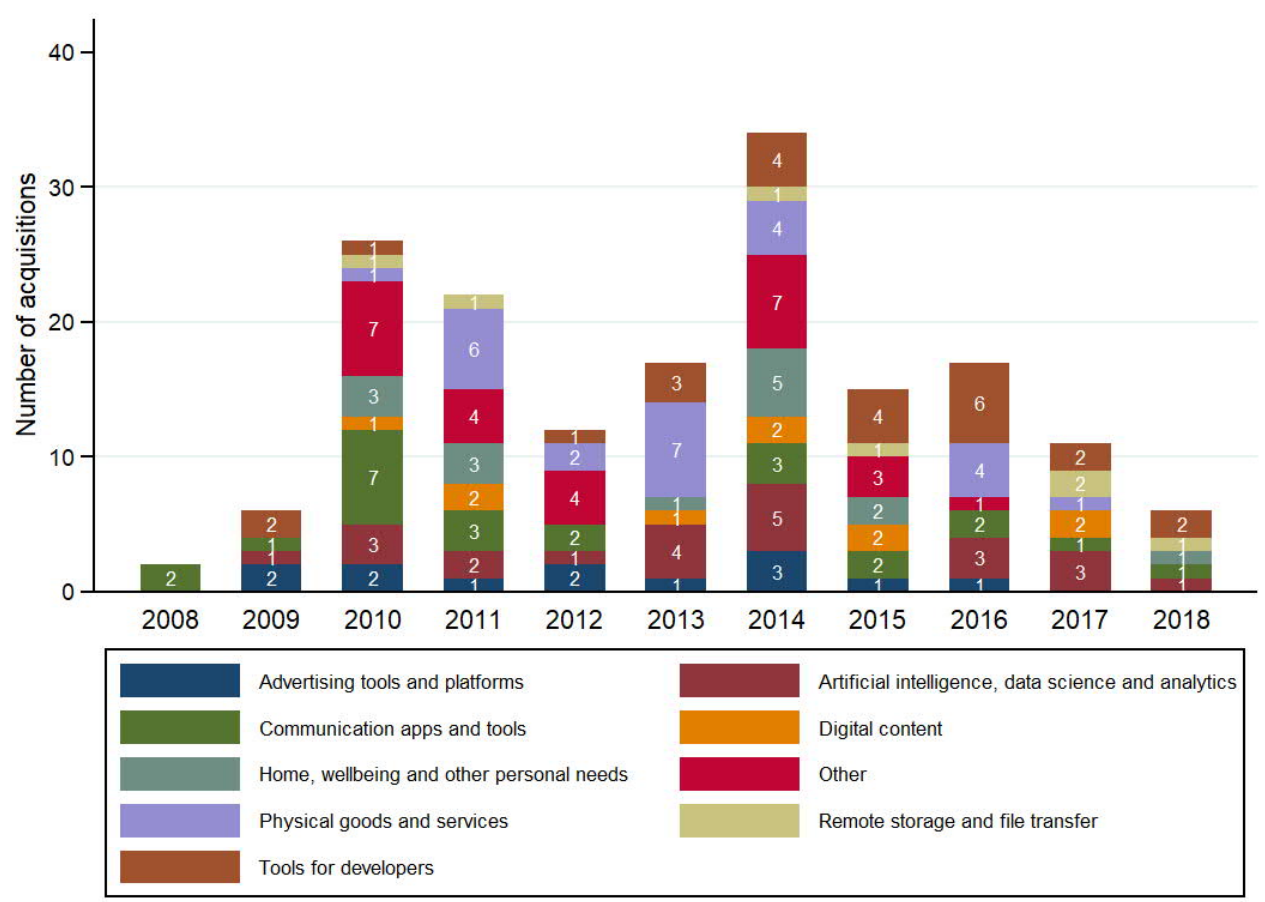

Source: authors based on Crunchbase data

Finally, Figure 4 suggests that Google has been active throughout the whole period with a peak of M\&A activity in 2014. Google's acquisitions do not follow a recognizable pattern and seem to be spread evenly across years and clusters. However, from 2013 to 2016, there were a number of acquisitions in the Tools for developers cluster, presumably to sustain Google's push into the mobile landscape that was expanding rapidly in those years. Finally, Google invested in Artificial Intelligence data science and analytics consistently throughout the period with the most notable acquisition being DeepMind in 2014.

Another striking feature of acquisitions carried out by Amazon, Facebook, and Google is the very young age of the targets. At the time of the acquisition, targets are four-years-old or younger in nearly $60 \%$ of cases. More specifically, the median age of Amazon's targets is 6.5 years; that of Facebook's targets is 2.5 years; and that of Google's targets is 4 years.

As the analysis in Section 4 shows, there are considerable difficulties in understanding the competitive implications of acquiring a young firm as, at that stage in their life cycle, their evolution is still uncertain and, thus, it is very difficult to determine if the target will grow to become a significant competitive force. Moreover, while non-horizontal mergers present significant scope for efficiencies, the realization of these efficiencies may enable incumbents of digital markets to preserve their leadership and preventing other market players from challenging them. 


\section{Review of two merger decisions taken by UK Authorities}

In this section we examine two widely discussed merger cases, Facebook/Instagram and Google/Wave, to evaluate the appropriateness of the decisions taken by the Authorities as well as subsequent market developments.

\subsection{Facebook/Instagram ${ }^{20}$}

The merger between Facebook and Instagram was cleared by the OFT on August 14, 2012. ${ }^{21}$ At that time, Instagram provided a free mobile photo app allowing users to take, modify and share photos on Instagram itself or on other social networks, thus making Instagram an input to social networks; whereas Facebook was a digital platform supplying social networking services and had recently launched a mobile photo app, Facebook Camera.

The Authorities considered three main ToHs. First, the merger would have made the competitive constraint that the parties exerted on each other in the market for the supply of photo apps disappear. This was dismissed based on the existence of several relatively stronger competitors that constrained Instagram more than Facebook and on the limited attractiveness of photo apps (including Instagram) to advertisers.

Second, although Instagram was not competing with Facebook for advertising revenues and had limited social network functionalities at the time of the merger, the Authorities' concern was that this could change in the future. The OFT dismissed this ToH because the available evidence did not show that Instagram was particularly well placed to compete against Facebook in the short run and there existed other firms that represented the main constraints on Facebook for brand advertising.

Finally, at the time, Instagram allowed photos to be easily reposted across a variety of competing social networking sites. The Authorities were concerned that the merged entity could either prevent or deteriorate the quality of those reposted photographs, with the intent of foreclosing Facebook's rivals. This ToH was dismissed as it was assumed that Instagram's appeal was attributable to the possibility to upload photos to other social networks and that limiting this possibility could cause some users to switch to other photo apps, thus being overall unprofitable for the merged entity.

\section{Assessment of ToHs}

Photo apps were not considered by the Authorities to be per se attractive to advertisers since users spent a limited amount of time on them; this argument was crucial for the dismissal of the actual competition in the supply of photo apps ToH. However, the opinions collected by the Authorities were not unanimous on this point. The data available shows that Instagram did generate significant user engagement compared to other photo apps and other social networks at the time of the merger. In September 2012, on average, Instagram's users spent over three times more time on the app than

\footnotetext{
${ }^{20}$ Emilio Calvano was not involved in the assessment of the Facebook/Instagram merger.

${ }^{21}$ Office of Fair Trading Decision of 14 August 2012 in Case ME/5525/12 - Facebook, Inc. / Instagram Inc.
} 
Photobucket's users, ${ }^{22}$ with the total minutes spent on the Instagram app thirty times greater than the minutes spent on Photobucket. Moreover, total minutes spent on Instagram by its users, as well the average minutes per user, were not dramatically different from the same figures for Twitter. ${ }^{23}$ This indicates that Instagram might have been different from other photo apps in terms of the user attention received and, consequently, its potential attractiveness to advertisers.

Given the evidence that was available to them, the Authorities might have also underestimated Instagram's potential to grow into a significant competitive force in the supply of social networking services.

The key argument for the dismissal of the foreclosure of rival social networks ToH was that the incentive to engage in a foreclosing strategy was missing as Instagram's popularity would have likely been negatively affected. However, the Authorities might have sought to more accurately ascertain the extent to which Instagram's popularity hinged on the ability of users to interact with other social network and, thus, its incentive to allow interoperability.

Most importantly, however, the Authorities failed to analyze the factors that drive the demand in the online advertising market. This could have affected the assessment of the two unilateral effects ToHs discussed above and made the set of ToHs considered by the Authorities incomplete. We identify three factors that seem to play a particularly important role in making one provider of advertising space more or less attractive from the perspective of advertisers and could have been better integrated in the Authorities' ToHs:

- User base's exclusivity. If certain users can only be reached by advertisers on one platform as they spend most of their time on it, clearly that platform has market power toward advertisers interested in reaching those users. Multi-homing users using different platforms might become exclusive if these platforms integrate through a merger.

- Platform's size. Larger platforms are more attractive to advertisers since they reduce the necessary transaction costs to reach a certain number of users and they remove the inefficiencies that might derive from placing ads on two or more independent platforms with potentially overlapping users, which might imply that some users end up being inefficiently over reached;

- Ability to target ads. Information on users' behavior collected by digital platforms provides insight into users' preferences and can be used to better target ads.

The merger could have caused competitive harm to the extent that it could have increased the merged entity's ability to exert market power by increasing user base's exclusivity. Moreover, the

\footnotetext{
${ }^{22}$ Photobucket was chosen for this comparison since it was the only photo app for which it was possible to retrieve data and that already had a significant presence in the market at the time of the merger.

${ }^{23}$ In particular, ComScore data shows that Instagram's users spent 16.4 million minutes on the app and the average minutes spent on the app by each user were 6.54; Photobucket's users spent 0.54 million minutes on the app and the average minutes spent on the app by each user were 1.84; finally, Twitter's users spent 12.23 million minutes on the app and the average minutes spent on the app by each user were 8.03 . The data collected from ComScore does not include the time spent by users under Wi-Fi connection: thus it underestimates the time spent on mobile devices. For this reason, time spent on mobile devices cannot be compared to time spent on desktop, limiting a meaningful comparison time spent on mobile devices only. Despite this limitation, these figures still provide an indication of Instagram's relative position. Photobucket was the only photo app for which these metrics were available that already represented a significant constraint on Instagram, as shown by data on registered and unique users provided by the parties at the time of the investigation.
} 
merger may have deprived other market participants of the opportunity to increase their size and better target ads to compete more effectively in the social network market.

\section{Assessment of post-merger market outcomes}

After the acquisition by Facebook, Instagram rapidly evolved into a different product, one that offers fully-fledged social network functionalities, such as direct messaging, photo tagging, and allows advertisers to place their ads on the platform. Facebook contributed to Instagram's growth by providing improved physical infrastructures as well as its expertise in social networks and advertising markets.

The number of Facebook users in the UK has been relatively stable over time, while the number of UK Instagram users has doubled over the same period, moving from 14 million in March 2015 to 26 million in September 2018 (see Figure 5Error! Reference source not found.).

\section{Figure 5: Number of monthly unique users of social networks in the UK (million)}

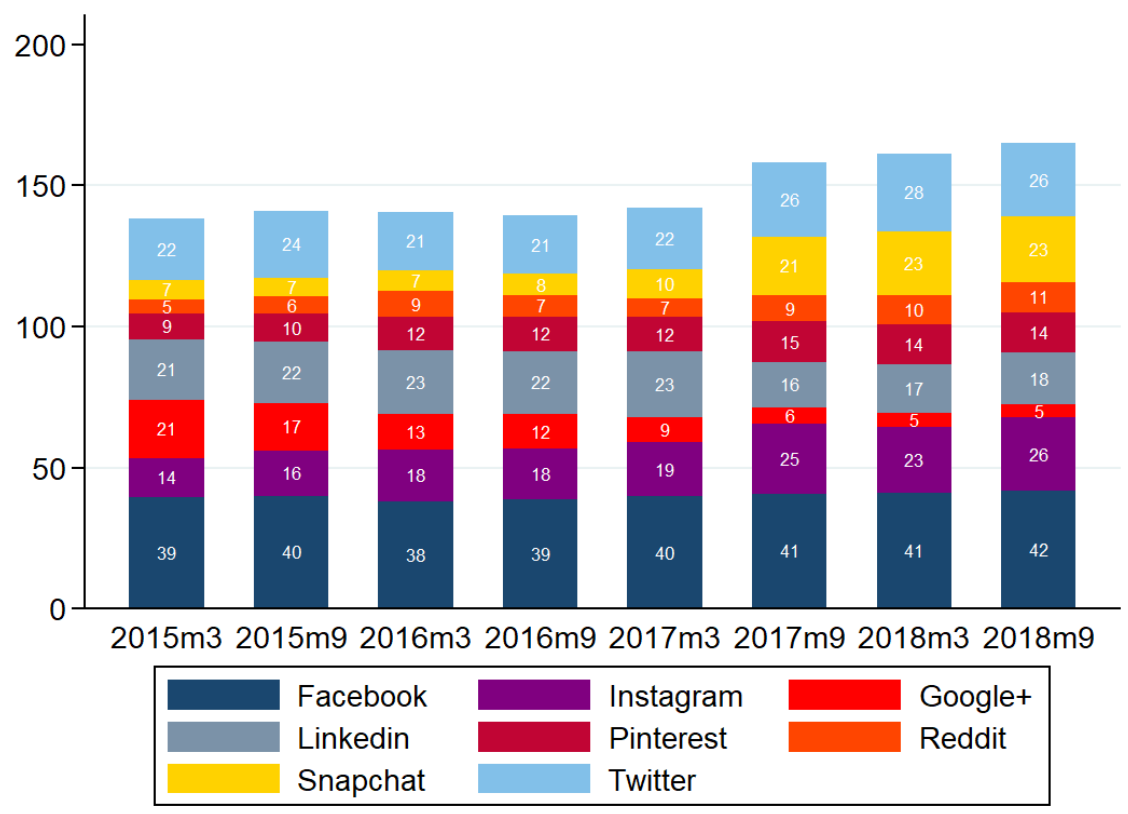

Source: authors based on ComScore data

In terms of time spent by users, Facebook has lost ground with respect to other social networks: the share of time spent by UK users has fallen from 86\% in 2015 to 58\% in 2018 (see Figure 6). Instagram's share has increased, going from $4 \%$ to $11 \%$ over the same period. Snapchat is the only 
other social network that is emerging as a significant challenger to the merged entity, with a share that reached $18 \%$ in $2018 .{ }^{24}$

Figure 6: Share of monthly time spent on social networks in the UK (\%)

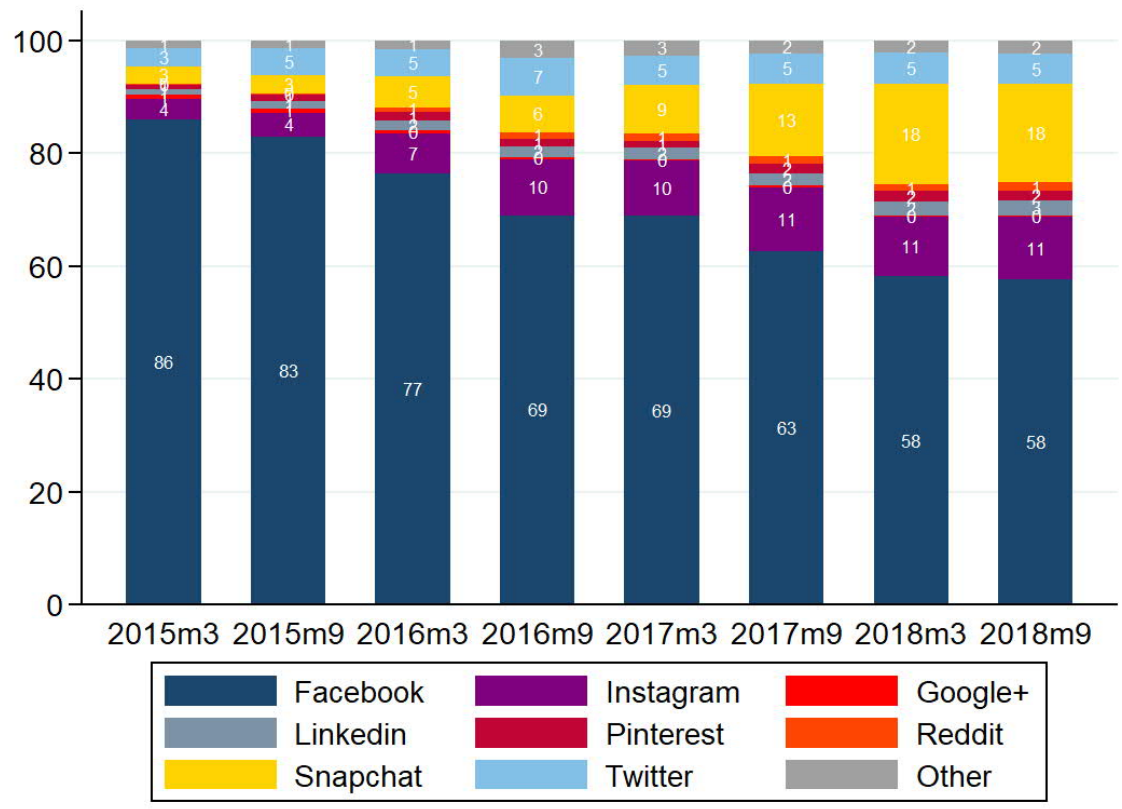

Source: authors based on ComScore data

On the other side of the market, Facebook's advertising revenue increased significantly despite the drop in time spent, and the gap between Facebook and other social networks has widened (see Figure 7: UK advertising revenue for the main social networks (million GBP)). This seems to suggest that the effectiveness of Facebook's advertising technology has significantly improved over time. Instagram started to monetize in the UK in 2015, and, since then, its revenues have increased significantly - as occurred for the number of users - largely exceeding the revenues earned by other platforms. The advertising revenue per hour spent on Facebook and Instagram is significantly larger than that of their rivals, suggesting that the merged entity is able to command higher prices.

\footnotetext{
${ }^{24}$ The evolution of the merging parties after the merger has been evaluated with respect to a market for social networks comprising those platforms that (i) enable the connection and interaction among users and, as a result, (ii) can leverage a deep understanding of users, their connections, and their preferences when selling advertising space.
} 
Figure 7: UK advertising revenue for the main social networks (million GBP)

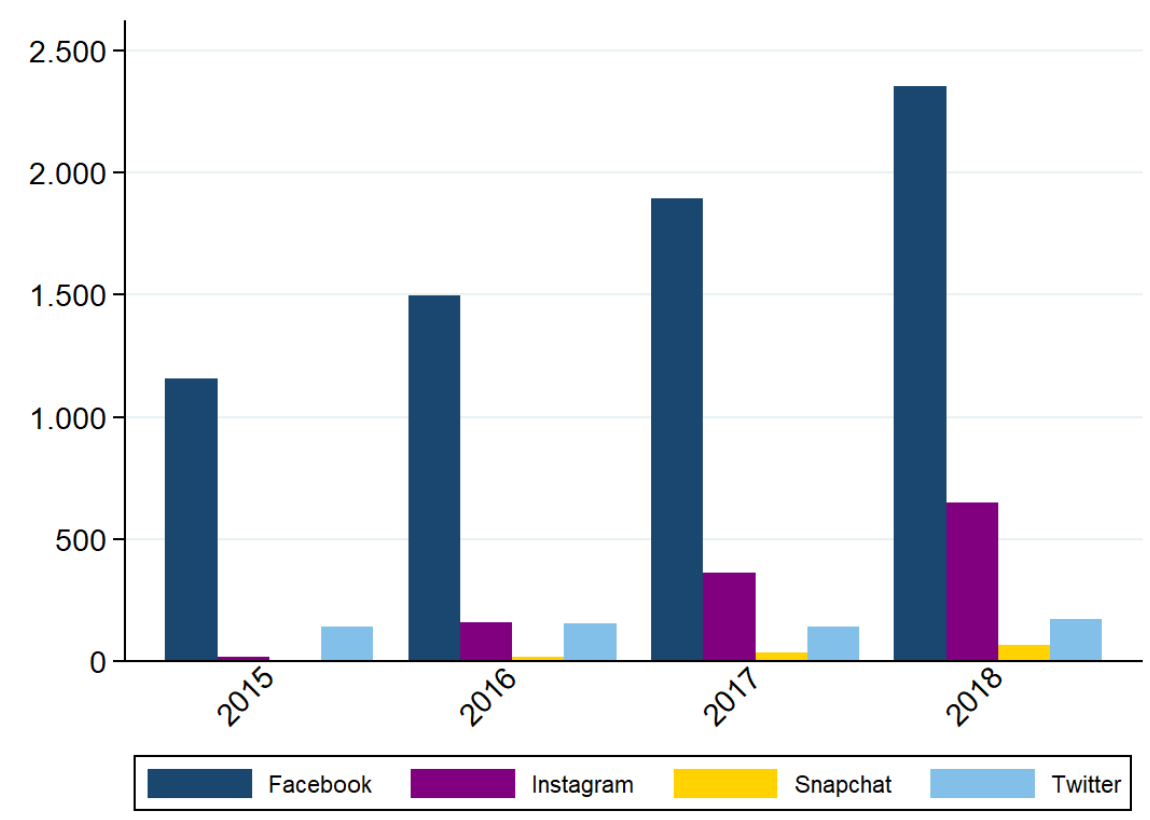

Source: authors based on eMarketer data (extracted on March 5, 2019)

This may be a result of the efficiencies achieved through the merger and/or of the exercise of market power by the merged entity. Indeed, the merger has likely contributed improving the position of the merged entity across many of the factors relevant to advertisers:

- Facebook uses and combines data from its own website and company-owned services, including Instagram, obtaining a much richer information set that is valuable for targeting ads.

- Facebook no longer faces the competitive constraint that might have been exerted by Instagram on users who cross-visit the two platforms; Error! Reference source not found.Figure 8 shows the percentage of Facebook users who visits other social networks. In 2015, 29\% of Facebook users were also visiting Instagram, ${ }^{25}$ and the percentage is increasing over time: in 2018, almost $60 \%$ of Facebook users are also on Instagram. The overlapping users between Facebook and Instagram foster Facebook's competitive advantage, as these users are more exclusive than they would have been if Facebook and Instagram were two separate entities.

- Facebook is able to reach a very wide set of social network users, as most users of other social networks also use Facebook, whereas the opposite occurs to a lesser extent. Indeed, in 2015, more than half of the users of the main social networks -Instagram, LinkedIn, Snapchat, and Twitter- were also visiting Facebook (see Figure 9). In 2018, almost all the users of these social networks were also visiting Facebook. By buying advertising spaces on Facebook, advertisers are able to reach almost all of Instagram, Twitter, LinkedIn, and Snapchat users. The opposite is not true: Figure 8 shows that, when selling advertising space on Twitter, indeed, advertisers

${ }^{25}$ Note that the available data only allows to measure overlapping users across pairs of social networks. However, the percentage of social network users who is cross-visiting a second platform, may also cross-visit an additional third platform. 
are only able to reach 59\% of Facebook users in 2018. On top of this, Facebook can also provide advertisers with access to users who cross-visit Instagram and other social networks. For instance, in 2018, 60\% of Twitter users cross-visited Instagram. This gives the merged entity the ability to reach those Twitter users who do not use Facebook but do use Instagram. This is particularly relevant as, thanks to Instagram, Facebook became able to reach demographics where it has lost ground over the past years. Indeed in 2017, the share of monthly time spent on Facebook by users aged 18-24 was as low as $8 \%$, whereas it was $43 \%$ in Instagram. By enhancing the size of Facebook and fostering users' engagement, the acquisition of Instagram substantially increased its attractiveness to advertisers and, in turn, its ability to exert market power. Clearly, the same holds for Instagram, albeit to a lesser extent. This would explain why both Facebook and Instagram advertising revenues increased pronouncedly more than any other competitor.

\section{Figure 8: Percentage of Facebook's users that visits the main social networks}

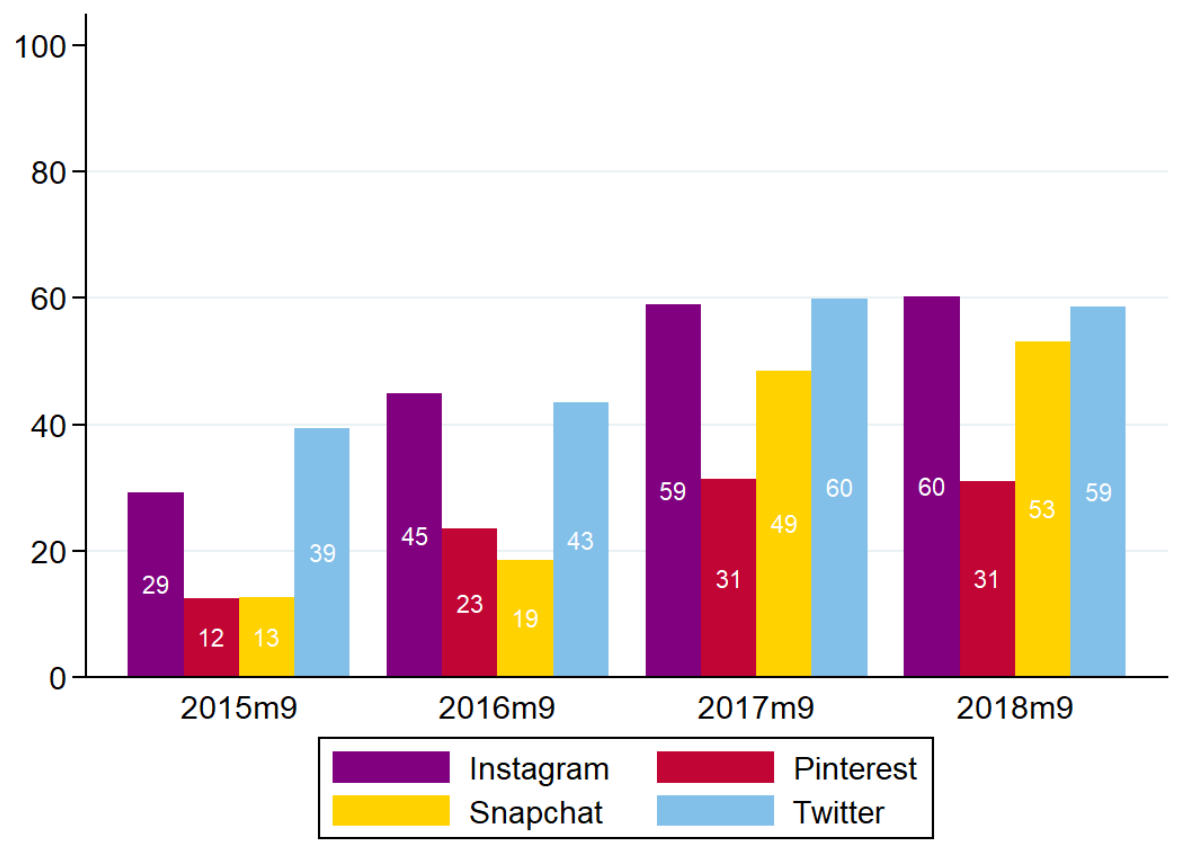

Source: authors based on ComScore data 
Figure 9: Percentage of other platforms' users that visits Facebook in the UK

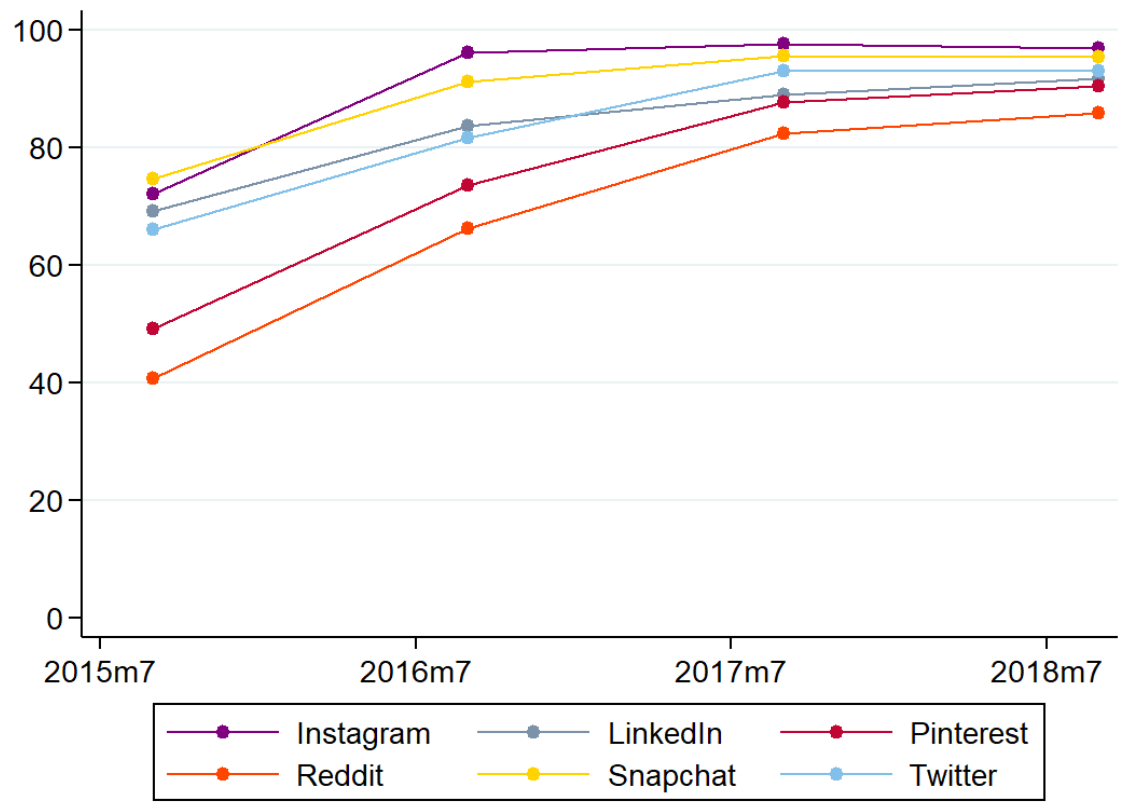

Source: authors based on ComScore data

Assessing whether this could be interpreted as a welfare loss and one that was caused by the Authorities' decision to clear the merger requires identifying what would have occurred to Instagram in the absence of the merger. Moreover, it also requires balancing the harmful effects of potential lower competition and the benefits of efficiencies. On the benefit side, the merger appears to have indeed generated efficiencies through increased functionalities and improved advertisement targeting to the benefit of users and advertisers. On the cost side, had Instagram become a popular social network on its own, Facebook would have faced a strong competitor in the social network market, which the merger eliminated. In this case, the merger specific efficiencies might have been insufficient to compensate for the loss of competition. Especially so, if one thinks that Instagram independent growth was a rare opportunity to shake the market and that the chances that a new credible Facebook competitor emerges are very thin. Although it is not possible to say whether this counterfactual scenario was the most likely, the Authorities might have preferred risking to commit a type I error because the cost of entrenching Facebook's market power could overcome the cost of foregone efficiencies.

\section{Conclusions on Facebook/Instagram}

The above analysis shows a number of gaps in the Authorities' assessment of the Facebook/Instagram merger.

First, the definition of the relevant market suffers of several drawbacks. Using the number of downloads to measure market shares may be problematic in the context of digital markets. The metric used should instead reflect actual usage. Moreover, differently from what the Authorities 
argued, at the time of the merger Instagram was generating significant user engagement. This made Instagram different from other photo apps as well as well placed to start monetizing its services by selling advertising space and, more importantly, to develop and offer social network functionalities. The Authorities indicated that Instagram was not particularly well placed to compete against Facebook in the supply of social network services. However, the evidence available to the Authorities would not seem to unambiguously support this conclusion.

Second, the incentives to foreclose were not carefully set out by the Authorities when assessing this ToH. They assumed that a strategy aimed at foreclosing rival social networks by preventing interoperability with Instagram would not have been profitable because Instagram's popularity hinged on the ability of its users to interact with their preferred social networks. However, available evidence showed that this was not necessarily the case. Indeed, Instagram did quickly decrease interoperability with other platforms following the merger, demonstrating that this strategy was profitable. ${ }^{26}$ The Authorities should have evaluated the incentive to foreclose in a more dynamic manner. Had Instagram grown as a result of the merger, and become a must-have among photo apps, the incentives to foreclose could have changed.

Third, the Authorities placed significant consideration to the functionalities that the merging parties' apps provided and whether these functionalities made the apps substitutes or complements. However, they failed to account for the role of consumer attention and competition in the advertising side of the market. Their analysis might have neglected some factors that drive advertisers' choices: chief among these are exclusivity of the user base, size of the user base, and accuracy in targeting. The Authorities could have assessed how the merger could have affected each of these.

The assessment of the market structure that has arisen since the merger shows that the acquisition of Instagram has provided a competitive advantage to the merged entity across all three dimensions, which has resulted in unmatched growth in terms of users and advertising revenues. However, there are also reasons to believe that Instagram's growth has significantly benefitted from the integration with Facebook: Snapchat's case shows that transforming users' attention into advertising revenue is no easy task and that Instagram's success in this respect has likely benefitted from Facebook's guidance and expertise.

Finally, whether the decision has ultimately harmed consumers also depends on the benefits accrued through the merger, which may have countervailed anti-competitive effects. Being able to monitor consumers' behaviour on its platform and on Instagram, Facebook can effectively target advertising and reduce inefficient ads duplications on its platforms. A part of increased functionalities, this may have generated additional benefits to consumers, which may have not arisen in the absence of the merger. These efficiencies seem also to be merger-specific, and it is

\footnotetext{
${ }^{26}$ At the end of 2012, Instagram changed the way that it interacts with other social networks. Instagram users were no longer able to embed a content uploaded to Instagram in their feed on social networks other than Twitter; rather, they were only able to share a link driving traffic back to Instagram. This has arguably deteriorated the quality of Twitter's users experience: Instagram photos no longer appeared on their Twitter's feed, but they were just posted as a link back to Instagram. This decision by the merged entity would seem to be consistent with the realization of the foreclosure ToH that was assessed (and dismissed) by the Authorities.
} 
difficult to assume that they would have arisen in a counterfactual scenario where Instagram was not acquired by Facebook or another social network.

\subsection{Google/Waze}

On November 11, 2013, the OFT cleared Google's acquisition of Waze. ${ }^{27}$ Google operated an Internet search engine and sold advertising space on its websites and on partner websites. Moreover, it offered Google Maps, a free application providing mapping and turn-by-turn navigation services. Waze provided another turn-by-turn navigation app that was only available on mobile devices.

The Authorities investigated two main ToHs. First, the transaction could significantly affect competition in the market for mobile turn-by-turn navigation applications, with the result of reducing the parties' incentives to innovate and the quality of the service offered to users. This ToH was dismissed because Waze had not reached a user base in the UK that was considered sufficient to build a map with coverage and accuracy comparable to Google's. Moreover, the existence of other turn-by-turn navigation apps - most notably Apple Maps - was found to exert relatively stronger constraints on Google. Second, Waze could represent a disruptive force in the market going forward. The Authorities dismissed this ToH because of the uncertainty in Waze's future growth projections. The scale reached by Waze in the UK was not sufficient for it to benefit from significant network effects that could accelerate its growth, there was uncertainty with respect to the effect of the partnerships that Waze was finalizing, and there would have remained other strong competitors.

\section{Assessment of ToHs}

The Authorities may have over-relied on the competitive constraint that Apple Maps would have exerted on the merged entity. Apple Maps was only available on iOS devices, which represented $30-31 \%$ of smartphone sales in the UK at the time of the merger and could represent an indirect constraint on Google Maps for Android devices only to the extent that Google cannot discriminate between the two OSs. If Google were to lower the quality of Google Maps on Android, for instance by introducing ads (which, being generally considered as a nuisance, would represent a drop in quality), Android users would not be able to switch to Apple Maps. The Authorities could have investigated whether such discrimination was feasible.

Regarding Waze's potential, there were signals that Waze had identified a promising path to growth. While lagging significantly behind Google Maps, Waze was among the most popular navigation apps among Android and iOS users. The evidence collected by the Authorities with respect to past growth and the opinions of third parties as well as of the merging parties themselves

${ }^{27}$ Office of Fair Trading Decision of 11 November 2013 in Case ME/6167/13 - Motorola Mobility Holding (Google, Inc.) / Waze Mobile Limited. 
clearly signaled that there was significant potential to Waze, as did the greater success that Waze had reached in other countries at the time of the merger.

Waze's business model, based on crowd-sourcing of most information needed to feed the app, was also a relevant factor pointing to possible future growth. Indeed, crowd-sourcing of information not only decreases entry costs by providing a cost-effective alternative to purchasing maps information from third parties; it also makes improvements to the app, in terms of maps accuracy and reliability of live traffic information, relatively less costly to implement.

As explained in Section 2.1, the installed user base could constitute a source of competitive advantage for Waze, which the Authorities referred to as first-mover advantage. Third parties consulted by the Authorities expressed concerns that it would have been difficult for an entrant to replicate the success achieved by Waze with an equivalent model. The OFT just considered that crowd-sourcing was not unique to Waze, but it did not assess the likelihood with which other operators could have successfully achieved a critical mass.

Relatedly, the OFT somewhat misinterpreted the role played by network effects in this market. Specifically, they did not, "consider that, on the basis of the evidence, Waze had achieved sufficient scale in the UK to the extent that it was benefitting from significant and insuperable network effects, or that this would lead to an acceleration in its future growth." ${ }^{28}$ However, the relevant question was not whether Waze already enjoyed insuperable network effects, but rather whether network effects could play a role in accelerating growth. Indeed, Waze had found a way to leverage its existing customer base: the larger such base, the more contributions to the quality of the maps and of the service in general; since better quality attracts more users, a positive feedback loop is created.

Overall, there may have been enough evidence for the Authorities to conclude that Waze could have become a relevant competitive force. Most importantly, the range of ToHs analyzed in the decision was incomplete. ToHs developed by the Authorities focused solely on the effect that the merger could have had on the users' side of the market. However, turn-by-turn navigation apps are provided to users for free and are monetized elsewhere. The Authorities could have explored monetization channels and evaluate whether the merger could have had an adverse effect in the markets where monetization occurs.

\section{Assessment of post-merger market outcomes}

Google and Waze both provide turn-by-turn navigation services, which are however fundamentally different in terms of their characteristics. Unlike Google Maps, the Waze map is user-generated and is mainly used by heavy drivers. By exploiting their complementarities, the merger between Google and Waze allowed the merging parties to improve their apps and realize some efficiencies.

${ }^{28}$ Office of Fair Trading Decision of 11 November 2013 in Case ME/6167/13, § 49. 
Since 2012, the number of Waze's active users has increased. In the years after the merger, Waze still represented one of the main alternatives to Google Maps for the provision of turn-by-turn navigation services, together with Apple Maps. Figure 10 shows the share of the various apps in the supply of turn-by-turn navigation apps, in terms of unique users, at the beginning of 2015 in the UK (the earliest date for which data is available after the merger took place). ${ }^{29}$ While substantially smaller than Google Maps and Apple Maps, Waze is the third app for number of unique users.

\section{Figure 10: Share of supply in turn-by-turn navigation apps, 2015m1 (\% of unique users)}

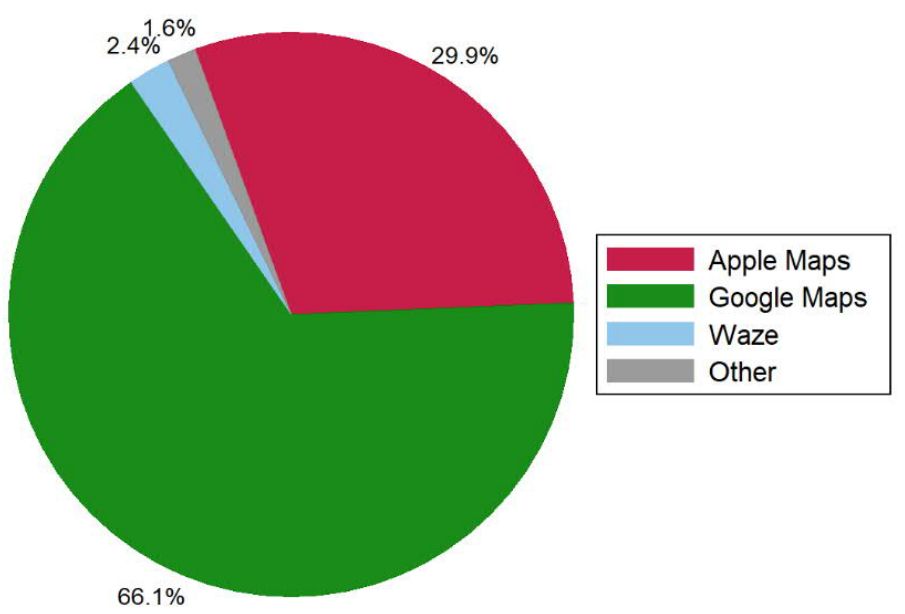

Source: authors based on ComScore data

At the time of its decision, the OFT relied on the fact that there were other providers of turn-byturn navigation apps, different from Waze, that would continue to represent strong competitive constraints on Google Maps, particularly Apple Maps. The evidence collected shows that after the merger Google has remained the main provider of turn-by-turn navigation services, with a share of $66 \%$, followed by Apple Maps (30\% share) and Waze (2\% share).

Few of the existing competitors seem to rely on crowd-sourced data and they attract very few users. This may be consistent with Waze's first mover advantage and with the concerns expressed by third parties that it would have been difficult for an entrant to replicate the success achieved by Waze with a similar model.

It should also be noted that Apple Maps continues to be available only on iOS devices, which may limit the extent to which it provides a competitive constraint on the merged entity.

\footnotetext{
${ }^{29}$ The shares are calculated based on the number of unique users in January 2015 provided by ComScore, which collects data only for navigation applications whose number of users is above a threshold ("Minimum Reporting Standard"). We do not expect results to be significantly different if those apps were instead included in the analysis. The Minimum Reporting Standard was equal to 149,000 unique users in January 2015.
} 
In its decision to clear the merger, the OFT did not take into account how the services offered through Google Maps and Waze are monetized. However, monetization channels were already relevant then and have arguably increased in their relevance over time. Mapping services can be directly monetized through advertising displayed in the navigation apps. In addition, mapping services can be monetized indirectly, by collecting, selling or otherwise exploiting location data, which is used by companies also for purposes other than advertising. The merger with Waze might have made Google an even more relevant provider of location data, reinforcing its competitive position for the provision of online advertising across all its services.

To causally assess the competitive effect of the merger, a counterfactual analysis is needed. There are a number of counterfactuals that could be considered: Waze could have grown on its own, been acquired by other digital companies, or would have not been able to survive. However, the evidence gathered on the market outcome evolution after the merger is not sufficient to select one of these counterfactuals as the most likely. In any case, the merger has enabled Google and Waze to exploit their complementarities and generate efficiencies. These efficiencies are clearly merger-specific and should be taken into account when assessing whether the decision has proved to be beneficial or detrimental to consumers.

\section{Conclusions on Google/Waze}

The Authorities' investigation at the time of the merger uncovered that Waze was a promising application in a market where users did not have many alternatives, with a promising business model and growth strategy. Yet, the Authorities were very cautious in the assessment of the evidence before them dismissing the potential competition $\mathrm{ToH}$ in part due to uncertainty in future market developments.

Further, the reliance on Apple Maps as a source of competitive constraints on the merged entity may have been overstated. If Google were to lower the quality of Google Maps on Android, Android users would not be able to switch to Apple Maps. Apple Maps could constrain Google Maps to the extent that Google cannot discriminate between the two platforms. The Authorities did not investigate whether this was the case, and simply relied on the existence of Apple Maps as a source of competitive constraint. The Authorities could have further investigated the ability of turnby-turn navigations apps to discriminate across operating system along with the costs users bear to switch from one operating system to another.

Finally, the Authorities did not explore the effects of the merger on several economic activities related to the provision of turn-by-turn navigation services, which represent the way these services are monetized. This is the result of an insufficient understanding of how the services provided by the merging parties are monetized, both directly and indirectly.

The market outcome assessment highlights the existence of multiple sources of complementarity between the two turn-by-turn navigation apps, which may have been exploited through the merger and contributed to the development the merging parties have witnessed in the years after the merger. In terms of choice, there remain few alternatives to the merging parties available to users 
for turn-by-turn navigation apps, especially for the Android environment. Moreover, the merger may have provided Google with yet another opportunity to reinforce its position in the markets where location data can be exploited, including advertising markets.

While there appear to be some gaps in the analysis undertaken by the Authorities, it is hard to say whether the clearance of the merger has led to a detrimental outcome for consumers. This depends on the development that Waze would have witnessed in the absence of the merger, i.e. the selected counterfactual. Even when compared to a counterfactual where Waze would have become a strong competitor, the assessment of the decision should also consider the potentially substantial efficiencies arisen from the merger, which may counterbalance the anti-competitive harm.

\section{Conclusions and Recommendations}

Our evaluation of past merger decisions taken by the UK Authorities reveals certain gaps in the way these cases were analyzed, despite the depth of the analyses carried out. Such gaps do not undermine the legitimacy of the Authorities' decisions and can be properly perceived today thanks to a better understanding of how digital markets work and the actual behavior of some market players that was highly uncertain at the time the mergers were investigated. Yet, we share the concern voiced by others that merger control enforcement has not proved able so far to cope with many of the new challenges posed by digital markets. More can and should be done. It might be that this will require a change in the legislation or a new regulator. We do not opine on this. However, we think that before undertaking such a complex and uncertain endeavor, competition authorities need to check whether more can be achieved within the existing legal framework. Therefore, we offer few suggestions as our concluding remarks.

- Network effects often make the structure of digital markets quite concentrated and barriers to entry rather high, making competition for the market the main mechanism left to discipline incumbents and potential competitors particularly valuable. Thus, the social costs of an incorrect clearance may be higher in digital markets than they are in traditional markets, which may justify a different, perhaps more interventionist, approach to digital markets.

- CAs may benefit from a better understanding of the markets for online advertising. These markets are particularly important, as they represent the way many digital services are monetized, yet the competitive dynamics prevailing therein are not well understood. A comprehensive market study into the digital advertising sector - such as the inquiry that the CMA is currently conducting - could be a good instrument to gain the necessary knowledge for future enforcement activity in the sector.

- CAs have not always consistently framed the competition issues they were looking at in a multisided setting, focusing their attention on the users' side of the market, somewhat overshadowing the other sides. All sides of a market need to be looked at jointly, as choices made by the platform on them are interdependent. 
- Current business models and monetization avenues should represent an unavoidable step for the development of a ToH because, quite simply, market power is not exerted for its own sake, but has the ultimate objective of increasing profits. Investigating the monetization strategy is also important because it can shed light on the rationale of the merger from the parties' perspective, making clear how the target brings value - that is, profits - to the acquirer.

- The time frame of two years, which represents the default for the assessment of some future market developments, such as entry, within merger investigations in many jurisdictions, may be somewhat limiting and could be extended when dealing with mergers in digital markets: even in the fast-moving digital landscape, becoming successful can take longer than two years.

- There is a large number of transactions being undertaken by digital incumbents. The value of the transaction may help CAs screen among those transactions to identify those that may warrant a more in-depth analysis of the merger, since it represents the magnitude of the effects (both beneficial and detrimental) associated to the transaction.

- Defining the counterfactual to a merger is always complex but may be especially so when one of the merging parties is a very young firm in the early stage of its development. Yet, predicting evolution is essential to understand whether the transaction will harm competition. Predicting evolution may benefit from improving the information gathering powers of CAs, for instance by using dawn raids in the context of merger investigations.

- CAs would need to be willing to accept more uncertainty in their counterfactual. Even after reinforcing the tools available, there will always be a certain degree of uncertainty as to the counterfactual chosen for the assessment of a merger. Future plans, no matter how carefully set out, are always subject to being unmade by unforeseen market events.

- A more speculative counterfactual may result in falling short of the meeting the legal tests CAs are required to satisfy to block a merger. However, as high tech markets evolve and pose new challenges, for CAs to be effective in the enforcement of merger policy, it may be necessary to test the boundaries of the substantive rules and of the applicable standard of proof. 


\section{References}

Ambrus, A., \& Argenziano, R. (2009). Asymmetric Networks in Two-Sided Markets. American Economic Journal: Microeconomics, 1(1), 17-52.

Anderson, S. P., \& Coate, S. (2005). Market Provision of Broadcasting: A Welfare Analysis. The Review of Economic Studies, 72(4), 947-972.

Argentesi, E., P. Buccirossi, E. Calvano, T. Duso, A. Marrazzo, \& S. Nava (2019). Assessment of merger control decisions in digital markets: Evaluation of past merger decisions in the UK digital sector. Retrieved from https://bit.ly/2pJp7xT

Armstrong, M. (2006). Competition in two-sided markets. The Rand Journal of Economics, $37(3), 668-691$.

Bajari, P., Chernozhukov, V., Hortaçsu, A., \& Suzuki, J. (2019). The Impact of Big Data on Firm Performance: An Empirical Investigation. American Economic Association, Papers and Proceedings, 109, 33-37.

Biglaiser, G., Calvano, E., \& Crémer, J. (2019). Incumbency advantage and its value. Journal of Economics \& Management Strategy, 28(1), 41-48

Biglaiser, G., \& Crémer, J. (2018). The value of incumbency in heterogenous networks. TSE Working Paper, n. 16-630.

Caillaud, B., \& Jullien, B. (2003). Chicken \& Egg: competition among intermediation service Providers. The Rand Journal of Economics, 34(2), 309-328.

Calvano, E., \& Polo, M. (2019). Market Power, competition and innovation in digital markets: A survey. Information Economics and Policy, forthcoming.

Cremer J., de Montjoye Y.-A., \& Schweitzer H. (2019). Competition Policy for the digital era. Final report. Retrieved from https://bit.ly/2JMr3g3

Cunningham, C., Ederer, F., \& Ma, S. (2018). Killer Acquisitions.

https://doi.org/10.2139/ssrn.3241707

de Cornière A. \& Taylor G. (2019). Upstream Bundling and Leverage of Market Power. CEPR Discussion Papers, No 13083.

Farrell, J., \& Saloner, G. (1986). Installed Base and Compatibility: Innovation, Product Preannouncements, and Predation. The American Economic Review, 76(5), 940-955.

Fudenberg, D., \& Tirole, J. (2000). Pricing a network good to deter entry. The Journal of Industrial Economics, 48(4), 373-390 
Furman, J., Coyle D., Fletcher A., McAuley D., \& Marsden P. (2019). Unlocking digital competition: Report of the Digital Competition Expert Panel. Retrieved from https://bit.ly/33jH58S

Halaburda, H., Jullien, B., \& Yehezkel, Y. (2018). Dynamic Competition with Network Externalities: Why History Matters. https://doi.org/10.2139/ssrn.2335716.

Hałaburda, H., \& Yehezkel, Y. (2016). The Role of Coordination Bias in Platform Competition. Journal of Economics \& Management Strategy, 25(2), 274-312.

Lambrecht, A., \& Tucker, C. E. (2015). Can Big Data Protect a Firm from Competition? https://doi.org/10.2139/ssrn.2705530.

Jeitschko, T. D., \& Tremblay, M. J. (2018). Platform Competition with Endogenous Homing. https://doi.org/10.2139/ssrn.2441190.

Katz, M. L., \& Shapiro, C. (1992). Product Introduction with Network Externalities. The Journal of Industrial Economics, 40(1), 55-83.

Prat, A., \& Valletti, T. M. (2019). Attention Oligopoly. https://doi.org/10.2139/ssrn.3197930.

Prufer, J., \& Schottmüller, C. (2017). Competing with Big Data.

https://doi.org/10.2139/ssrn.2918726.

Rasmusen, E. (1988). Entry for Buyout. The Journal of Industrial Economics, 36(3), 281-299.

Rochet, J. and Tirole, J. (2003), Platform competition in two-sided markets. Journal of the European Economic Association, 1: 990-1029.

Rochet, J.-C., \& Tirole, J. (2006). Two-sided markets: a progress report. The Rand Journal of Economics, 37(3), 645-667.

Rubinfeld, D. L., \& Gal, M. S. (2017). Access Barriers to Big Data. Arizona Law Review, 59, 339-381.

Schaefer, M., and Sapi, G., \& Lorincz, S. (2018). The effect of big data on recommendation quality: The example of internet search. DIW Discussion Papers 1730.

Scott Morton F., Bouvier P., Ezrachi A., Jullien B., Katz R., Kimmelman G., Melamed A. D., \& Morgenstern J. (2019). Study of Digital Platforms. Market Structure and Antitrust Subcommittee. Retrieved from https://bit.ly/2WIVjOd 


\section{Appendix: list of past transactions}

Table A.1: List of acquisitions made by Amazon

\begin{tabular}{|c|c|c|}
\hline Name of target & Cluster & Sub-cluster \\
\hline 2lemetry & Tools for developers & \\
\hline AbeBooks & Physical goods and services & Retail \\
\hline Amie Street & Digital content & Video/Music \\
\hline Annapurna Labs & Remote storage and file transfer & \\
\hline AppThwack & Physical goods and services & Robotics \\
\hline Audible.com & Digital content & E-books/News \\
\hline Avalon Books & Physical goods and services & Other \\
\hline Biba Systems & Communication apps and tools & Email and office communication \\
\hline Blink Home & Physical goods and services & Electronic devices and components \\
\hline Body Labs & $\begin{array}{l}\text { Artificial intelligence, data science } \\
\text { and analytics }\end{array}$ & Artificial Intelligence \\
\hline Box Office Mojo & Other & \\
\hline BuyVIP & Physical goods and services & Retail \\
\hline Cloud9 IDE & Tools for developers & \\
\hline ClusterK & Remote storage and file transfer & \\
\hline comiXology & Digital content & E-books/News \\
\hline Curse, Inc. & Digital content & Games \\
\hline Do.com & Communication apps and tools & Email and office communication \\
\hline Double Helix Games & Digital content & Games \\
\hline Elemental Technologies & Remote storage and file transfer & \\
\hline Emvantage Payments Pvt. Ltd. & Other & \\
\hline Evi & $\begin{array}{l}\text { Artificial intelligence, data science } \\
\text { and analytics }\end{array}$ & Artificial Intelligence \\
\hline Fabric.com & Physical goods and services & Retail \\
\hline GameSparks & Tools for developers & \\
\hline Goo Technologies & Other & \\
\hline Goodreads & Communication apps and tools & Topic specific platform \\
\hline Graphiq & $\begin{array}{l}\text { Artificial intelligence, data science } \\
\text { and analytics }\end{array}$ & Data science and analytics \\
\hline Harvest.ai & $\begin{array}{l}\text { Artificial intelligence, data science } \\
\text { and analytics }\end{array}$ & Artificial Intelligence \\
\hline IVONA Software & $\begin{array}{l}\text { Artificial intelligence, data science } \\
\text { and analytics }\end{array}$ & Artificial Intelligence \\
\hline Kiva Systems & Physical goods and services & Robotics \\
\hline Lexcycle & Digital content & E-books/News \\
\hline Liquavista & Physical goods and services & Electronic devices and components \\
\hline LoveFilm & Physical goods and services & Retail \\
\hline More & Physical goods and services & Retail \\
\hline NICE & Remote storage and file transfer & \\
\hline OpenSCG & Remote storage and file transfer & \\
\hline PillPack & $\begin{array}{l}\text { Home, wellbeing and other personal } \\
\text { needs }\end{array}$ & \\
\hline Pushbutton & Digital content & Video/Music \\
\hline Quidsi & Physical goods and services & Retail \\
\hline Reflexive Entertainment & Digital content & Games \\
\hline Ring & Physical goods and services & Electronic devices and components \\
\hline Safaba Translation Systems & $\begin{array}{l}\text { Artificial intelligence, data science } \\
\text { and analytics }\end{array}$ & Artificial Intelligence \\
\hline
\end{tabular}




\begin{tabular}{|c|c|c|}
\hline Shelfari & Communication apps and tools & Topic specific platform \\
\hline Shoefitr & $\begin{array}{l}\text { Home, wellbeing and other personal } \\
\text { needs }\end{array}$ & \\
\hline SnapTell & $\begin{array}{l}\text { Artificial intelligence, data science } \\
\text { and analytics }\end{array}$ & Artificial Intelligence \\
\hline Souq.com & Physical goods and services & Retail \\
\hline Sqrrl & $\begin{array}{l}\text { Artificial intelligence, data science } \\
\text { and analytics }\end{array}$ & Data science and analytics \\
\hline Stanza & $\begin{array}{l}\text { Digital content } \\
\end{array}$ & E-books/News \\
\hline Tapzo & $\begin{array}{l}\text { Home, wellbeing and other personal } \\
\text { needs }\end{array}$ & \\
\hline Teachstreet & $\begin{array}{l}\text { Home, wellbeing and other personal } \\
\text { needs }\end{array}$ & \\
\hline TenMarks Education, Inc. & $\begin{array}{l}\text { Home, wellbeing and other personal } \\
\text { needs }\end{array}$ & \\
\hline The Book Depository & Physical goods and services & Retail \\
\hline Thinkbox Software & Tools for developers & \\
\hline Toby Press & Physical goods and services & Other \\
\hline Touchco & Other & \\
\hline Twitch & Communication apps and tools & Topic specific platform \\
\hline Whole Foods Market & Physical goods and services & Retail \\
\hline Wing.ae & Physical goods and services & Retail \\
\hline Woot & Physical goods and services & Retail \\
\hline Yap & $\begin{array}{l}\text { Artificial intelligence, data science } \\
\text { and analytics }\end{array}$ & Artificial Intelligence \\
\hline Zappos & Physical goods and services & Retail \\
\hline
\end{tabular}

Table A.2: List of acquisitions made by Facebook

\begin{tabular}{|c|c|c|}
\hline Name of target & Cluster & Sub-cluster \\
\hline Acrylic Software & Other & \\
\hline Ascenta & Physical goods and services & Robotics \\
\hline Atlas solutions & Advertising tools and platforms & \\
\hline BELUGA & Communication apps and tools & Direct messaging and calls \\
\hline Bloomsbury AI & $\begin{array}{l}\text { Artificial intelligence, data science } \\
\text { and analytics }\end{array}$ & Artificial Intelligence \\
\hline Branch & Communication apps and tools & Direct messaging and calls \\
\hline Caffeinatedmind & Remote storage and file transfer & \\
\hline Chai Labs & $\begin{array}{l}\text { Artificial intelligence, data science } \\
\text { and analytics }\end{array}$ & Artificial Intelligence \\
\hline Confirm & $\begin{array}{l}\text { Artificial intelligence, data science } \\
\text { and analytics }\end{array}$ & Artificial Intelligence \\
\hline ConnectU & $\begin{array}{c}\text { Other } \\
\end{array}$ & \\
\hline CrowdTangle & $\begin{array}{l}\text { Artificial intelligence, data science } \\
\text { and analytics }\end{array}$ & Data science and analytics \\
\hline DayTum & $\begin{array}{l}\text { Home, wellbeing and other } \\
\text { personal needs }\end{array}$ & \\
\hline Divvyshot & Communication apps and tools & Photo apps \\
\hline Drop.io & Remote storage and file transfer & \\
\hline Face.com & $\begin{array}{l}\text { Artificial intelligence, data science } \\
\text { and analytics }\end{array}$ & Artificial Intelligence \\
\hline
\end{tabular}




\begin{tabular}{|c|c|c|}
\hline Faciometrics & $\begin{array}{l}\text { Artificial intelligence, data science } \\
\text { and analytics }\end{array}$ & Artificial Intelligence \\
\hline Fayteq & Other & \\
\hline FB.com domain name & Other & \\
\hline Friend.ly & Communication apps and tools & Other \\
\hline FriendFeed & Communication apps and tools & Aggregators \\
\hline Friendster & Communication apps and tools & Topic specific platform \\
\hline Glancee & Communication apps and tools & Other \\
\hline Gowalla & Communication apps and tools & Topic specific platform \\
\hline Hot Potato & Communication apps and tools & Topic specific platform \\
\hline Hot Studio & Tools for developers & \\
\hline Infiniled & Physical goods and services & Electronic devices and components \\
\hline Instagram & Communication apps and tools & Photo apps \\
\hline Jibbigo & $\begin{array}{l}\text { Artificial intelligence, data science } \\
\text { and analytics }\end{array}$ & Artificial Intelligence \\
\hline Karma & $\begin{array}{l}\text { Home, wellbeing and other } \\
\text { personal needs }\end{array}$ & \\
\hline Lightbox.com & Communication apps and tools & Photo apps \\
\hline Little Eye Labs & Tools for developers & \\
\hline Liverail & Advertising tools and platforms & \\
\hline MailRank & Communication apps and tools & Email and office communication \\
\hline Masquerade & Communication apps and tools & Other \\
\hline Monoidics & $\begin{array}{l}\text { Artificial intelligence, data science } \\
\text { and analytics }\end{array}$ & Artificial Intelligence \\
\hline Nascent Objects & Physical goods and services & Electronic devices and components \\
\hline Nextstop & Communication apps and tools & Topic specific platform \\
\hline Octazen & Communication apps and tools & Other \\
\hline Oculus VR & Physical goods and services & Other \\
\hline Onavo & $\begin{array}{l}\text { Artificial intelligence, data science } \\
\text { and analytics }\end{array}$ & Data science and analytics \\
\hline Osmeta & Other & \\
\hline Ozlo & $\begin{array}{l}\text { Artificial intelligence, data science } \\
\text { and analytics }\end{array}$ & Artificial Intelligence \\
\hline Parse & Tools for developers & \\
\hline Pebbles & Tools for developers & \\
\hline PrivateCore & Remote storage and file transfer & \\
\hline ProtoGeo Oy & $\begin{array}{l}\text { Home, wellbeing and other } \\
\text { personal needs }\end{array}$ & \\
\hline Pryte & $\begin{array}{l}\text { Home, wellbeing and other } \\
\text { personal needs }\end{array}$ & \\
\hline Push Pop Press & Digital content & E-books/News \\
\hline Quickfire & Remote storage and file transfer & \\
\hline RecRec & Tools for developers & \\
\hline Redkix & Communication apps and tools & Email and office communication \\
\hline Refdash & Other & \\
\hline Rel8tion & Advertising tools and platforms & \\
\hline ShareGrove & Communication apps and tools & Direct messaging and calls \\
\hline snaptu & Tools for developers & \\
\hline Sofa & Tools for developers & \\
\hline Spaceport & Tools for developers & \\
\hline Spool & $\begin{array}{l}\text { Home, wellbeing and other } \\
\text { personal needs }\end{array}$ & \\
\hline SportStream & $\begin{array}{l}\text { Artificial intelligence, data science } \\
\text { and analytics }\end{array}$ & Data science and analytics \\
\hline Strobe & Tools for developers & \\
\hline
\end{tabular}




\begin{tabular}{ccc}
\hline Surreal Vision & Physical goods and services & Robotics \\
\hline Tagtile & Advertising tools and platforms & Other \\
\hline tbh(app) & Communication apps and tools & Retail \\
\hline TheFind & Physical goods and services & Aggregators \\
\hline Threadsy & Communication apps and tools & Other \\
\hline Two Big Ears & Physical goods and services & Electronic devices and components \\
\hline Vidpresso & Communication apps and tools & Video/Music \\
\hline WaveGroup Sound & Digital content & \\
\hline WhatsApp & Communication apps and tools & Direct messaging and calls \\
\hline Wit.ai & Tools for developers & \\
\hline Zurich eye & Tools for developers &
\end{tabular}

Source: authors based on Crunchbase data

Table A.3: List of acquisitions made by Google

\begin{tabular}{|c|c|c|}
\hline Name of target & Cluster & Sub-cluster \\
\hline $60 \mathrm{db}$ & Digital content & E-books/News \\
\hline Aardvark & Communication apps and tools & Other \\
\hline Admeld & Advertising tools and platforms & \\
\hline AdMob & Advertising tools and platforms & \\
\hline Adometry & Advertising tools and platforms & \\
\hline Agawi & Digital content & Video/Music \\
\hline Agnilux & Physical goods and services & Electronic devices and components \\
\hline AIMatter & $\begin{array}{l}\text { Artificial intelligence, data science } \\
\text { and analytics }\end{array}$ & Artificial Intelligence \\
\hline Alpental Technologies & Physical goods and services & Electronic devices and components \\
\hline Angstro & Communication apps and tools & Aggregators \\
\hline Anvato & Tools for developers & \\
\hline API.AI & $\begin{array}{l}\text { Artificial intelligence, data science } \\
\text { and analytics }\end{array}$ & Artificial Intelligence \\
\hline Apigee & Tools for developers & \\
\hline AppBridge & Remote storage and file transfer & \\
\hline Appetas & Other & \\
\hline AppJet & Tools for developers & \\
\hline Appurify & Tools for developers & \\
\hline Apture & $\begin{array}{l}\text { Home, wellbeing and other personal } \\
\text { needs }\end{array}$ & \\
\hline Autofuss & Advertising tools and platforms & \\
\hline BandPage & Communication apps and tools & Topic specific platform \\
\hline BeatThatQuote.com & Physical goods and services & Retail \\
\hline bebop & Remote storage and file transfer & \\
\hline Behavio & $\begin{array}{l}\text { Artificial intelligence, data science } \\
\text { and analytics }\end{array}$ & Artificial Intelligence \\
\hline Bitium & Remote storage and file transfer & \\
\hline Bitspin & $\begin{array}{l}\text { Home, wellbeing and other personal } \\
\text { needs }\end{array}$ & \\
\hline BlindType & $\begin{array}{l}\text { Home, wellbeing and other personal } \\
\text { needs }\end{array}$ & \\
\hline Bot \& Dolly & Physical goods and services & Robotics \\
\hline BufferBox & Physical goods and services & Retail \\
\hline Bump & Tools for developers & \\
\hline BumpTop & $\begin{array}{l}\text { Home, wellbeing and other personal } \\
\text { needs }\end{array}$ & \\
\hline Cask & Tools for developers & \\
\hline Channel Intelligence & Physical goods and services & Retail \\
\hline
\end{tabular}




\begin{tabular}{|c|c|c|}
\hline Clever Sense & $\begin{array}{l}\text { Home, wellbeing and other personal } \\
\text { needs }\end{array}$ & \\
\hline Cronologics & Physical goods and services & Electronic devices and components \\
\hline DailyDeal & Physical goods and services & Retail \\
\hline Dark Blue Labs \& Vision Factory & $\begin{array}{l}\text { Artificial intelligence, data science } \\
\text { and analytics }\end{array}$ & Artificial Intelligence \\
\hline Dealmap & Physical goods and services & Retail \\
\hline DeepMind Technologies & $\begin{array}{l}\text { Artificial intelligence, data science } \\
\text { and analytics }\end{array}$ & Data science and analytics \\
\hline Digisfera & Other & \\
\hline Director & Advertising tools and platforms & \\
\hline Divide & $\begin{array}{l}\text { Home, wellbeing and other personal } \\
\text { needs }\end{array}$ & \\
\hline DNNresearch Inc. & $\begin{array}{l}\text { Artificial intelligence, data science } \\
\text { and analytics }\end{array}$ & Artificial Intelligence \\
\hline DocVerse & Other & \\
\hline drawElements & Tools for developers & \\
\hline Dropcam & Physical goods and services & Electronic devices and components \\
\hline eBook Technologies & Other & \\
\hline Emu & Communication apps and tools & Email and office communication \\
\hline Episodic & Digital content & Video/Music \\
\hline Eyefluence & Physical goods and services & Other \\
\hline Fabric & Tools for developers & \\
\hline FameBit & Advertising tools and platforms & \\
\hline Firebase & Tools for developers & \\
\hline FlexyCore & Tools for developers & \\
\hline Flutter & $\begin{array}{l}\text { Artificial intelligence, data science } \\
\text { and analytics }\end{array}$ & Artificial Intelligence \\
\hline Fly Labs & Other & \\
\hline Fridge & Communication apps and tools & Direct messaging and calls \\
\hline Gecko Design & Other & \\
\hline Gizmo5 & Communication apps and tools & Direct messaging and calls \\
\hline Global IP Solutions & Communication apps and tools & Direct messaging and calls \\
\hline GraphicsFuzz & Tools for developers & \\
\hline Green Parrot Pictures & Other & \\
\hline GreenThrottle & Digital content & Games \\
\hline Halli Labs & $\begin{array}{l}\text { Artificial intelligence, data science } \\
\text { and analytics }\end{array}$ & Artificial Intelligence \\
\hline Holomni & Physical goods and services & Robotics \\
\hline HTC (portions) & Physical goods and services & Electronic devices and components \\
\hline Impermium & Other & \\
\hline Incentive Targeting Inc. & Advertising tools and platforms & \\
\hline Industrial Perception & $\begin{array}{l}\text { Artificial intelligence, data science } \\
\text { and analytics }\end{array}$ & Artificial Intelligence \\
\hline Instantiations & Tools for developers & \\
\hline Invite Media & Advertising tools and platforms & \\
\hline Jambool & Other & \\
\hline Jetpac & Communication apps and tools & Photo apps \\
\hline Jibe Mobile & Communication apps and tools & Direct messaging and calls \\
\hline Kaggle & $\begin{array}{l}\text { Artificial intelligence, data science } \\
\text { and analytics }\end{array}$ & Data science and analytics \\
\hline Katango & Communication apps and tools & Other \\
\hline Kifi & $\begin{array}{l}\text { Artificial intelligence, data science } \\
\text { and analytics }\end{array}$ & Data science and analytics \\
\hline LabPixies & Other & \\
\hline
\end{tabular}




\begin{tabular}{|c|c|c|}
\hline LaunchKit & Tools for developers & \\
\hline Launchpad Toys & $\begin{array}{l}\text { Home, wellbeing and other personal } \\
\text { needs }\end{array}$ & \\
\hline LeapDroid & Tools for developers & \\
\hline Lift Labs & Physical goods and services & Electronic devices and components \\
\hline Like.com & $\begin{array}{l}\text { Artificial intelligence, data science } \\
\text { and analytics }\end{array}$ & Artificial Intelligence \\
\hline Limes Audio & Communication apps and tools & Direct messaging and calls \\
\hline Makani Power & Physical goods and services & Other \\
\hline mDialog & Advertising tools and platforms & \\
\hline Meebo & Communication apps and tools & Direct messaging and calls \\
\hline Meka Robotics & Physical goods and services & Robotics \\
\hline Metaweb & Other & \\
\hline Milk, Inc & Tools for developers & \\
\hline Moodstocks & Tools for developers & \\
\hline Motorola Mobility & Physical goods and services & Electronic devices and components \\
\hline MyEnergy & $\begin{array}{l}\text { Home, wellbeing and other personal } \\
\text { needs }\end{array}$ & \\
\hline Nest Labs & $\begin{array}{l}\text { Home, wellbeing and other personal } \\
\text { needs }\end{array}$ & \\
\hline Next New Networks & $\begin{array}{c}\text { Digital content } \\
\end{array}$ & Video/Music \\
\hline Nik Software, Inc. & Other & \\
\hline Odysee & Communication apps and tools & Photo apps \\
\hline Omnisio & Communication apps and tools & Other \\
\hline On2 & Tools for developers & \\
\hline Onward & $\begin{array}{l}\text { Artificial intelligence, data science } \\
\text { and analytics }\end{array}$ & Artificial Intelligence \\
\hline Orbitera & Physical goods and services & Retail \\
\hline Owlchemy Labs & Digital content & Games \\
\hline Oyster & Digital content & E-books/News \\
\hline Phonetic Arts & $\begin{array}{l}\text { Artificial intelligence, data science } \\
\text { and analytics }\end{array}$ & Artificial Intelligence \\
\hline Picnik & Communication apps and tools & Photo apps \\
\hline Pie & Communication apps and tools & Email and office communication \\
\hline PittPatt & $\begin{array}{l}\text { Artificial intelligence, data science } \\
\text { and analytics }\end{array}$ & Artificial Intelligence \\
\hline Pixate & Tools for developers & \\
\hline Plannr & Communication apps and tools & Email and office communication \\
\hline PlinkArt & $\begin{array}{l}\text { Artificial intelligence, data science } \\
\text { and analytics }\end{array}$ & \\
\hline Polar & Communication apps and tools & Other \\
\hline Pulse.io & Tools for developers & \\
\hline Punchd & Physical goods and services & Retail \\
\hline PushLife & Remote storage and file transfer & \\
\hline Quest Visual & $\begin{array}{l}\text { Artificial intelligence, data science } \\
\text { and analytics }\end{array}$ & Artificial Intelligence \\
\hline Quickoffice & Other & \\
\hline Quiksee & Other & \\
\hline Qwiklabs & Tools for developers & \\
\hline Rangespan & $\begin{array}{l}\text { Artificial intelligence, data science } \\
\text { and analytics }\end{array}$ & Data science and analytics \\
\hline reCAPTCHA & $\begin{array}{l}\text { Artificial intelligence, data science } \\
\text { and analytics }\end{array}$ & Artificial Intelligence \\
\hline Red Hot Labs & Advertising tools and platforms & \\
\hline Redwood Robotics & Physical goods and services & Robotics \\
\hline
\end{tabular}




\begin{tabular}{|c|c|c|}
\hline RelativeWave & Tools for developers & \\
\hline Relay Media & Tools for developers & \\
\hline reMail & Communication apps and tools & Email and office communication \\
\hline Revolv & $\begin{array}{l}\text { Home, wellbeing and other personal } \\
\text { needs }\end{array}$ & \\
\hline RightsFlow & Other & \\
\hline Ruba.com & $\begin{array}{l}\text { Home, wellbeing and other personal } \\
\text { needs }\end{array}$ & \\
\hline SageTV & $\begin{array}{l}\text { Digital content } \\
\end{array}$ & Video/Music \\
\hline SayNow & Communication apps and tools & Direct messaging and calls \\
\hline SCHAFT, Inc. & Physical goods and services & Robotics \\
\hline Senosis & $\begin{array}{l}\text { Home, wellbeing and other personal } \\
\text { needs }\end{array}$ & \\
\hline Simplify Media & Remote storage and file transfer & \\
\hline Skillman \& Hackett & Tools for developers & \\
\hline Skybox Imaging & $\begin{array}{l}\text { Artificial intelligence, data science } \\
\text { and analytics }\end{array}$ & Data science and analytics \\
\hline SlickLogin & Other & \\
\hline Slide.com & Communication apps and tools & Other \\
\hline SocialDeck, Inc. & Advertising tools and platforms & \\
\hline SocialGrapple & $\begin{array}{l}\text { Artificial intelligence, data science } \\
\text { and analytics }\end{array}$ & Data science and analytics \\
\hline Softcard & Other & \\
\hline Songza & Digital content & Video/Music \\
\hline Sparrow & Communication apps and tools & Email and office communication \\
\hline spider.io & Other & \\
\hline Stackdriver & Remote storage and file transfer & \\
\hline Synergyse & Other & \\
\hline Talaria Technologies & Tools for developers & \\
\hline Tenor & Communication apps and tools & Other \\
\hline Teracent & Advertising tools and platforms & \\
\hline Thrive Audio & Tools for developers & \\
\hline Timeful & $\begin{array}{l}\text { Home, wellbeing and other personal } \\
\text { needs }\end{array}$ & \\
\hline Titan Aerospace & Physical goods and services & Robotics \\
\hline TNC & Communication apps and tools & Topic specific platform \\
\hline TxVia & $\begin{array}{c}\text { Other } \\
\end{array}$ & \\
\hline Urban Engines & $\begin{array}{l}\text { Artificial intelligence, data science } \\
\text { and analytics }\end{array}$ & Data science and analytics \\
\hline Velostrata & Remote storage and file transfer & \\
\hline Vidmaker & Other & \\
\hline Viewdle & $\begin{array}{l}\text { Artificial intelligence, data science } \\
\text { and analytics }\end{array}$ & Artificial Intelligence \\
\hline VirusTotal.com & $\begin{array}{c}\text { Other } \\
\end{array}$ & \\
\hline Wavii & Digital content & E-books/News \\
\hline Waze & $\begin{array}{l}\text { Home, wellbeing and other personal } \\
\text { needs }\end{array}$ & \\
\hline Webpass & Physical goods and services & Other \\
\hline Widevine Technologies & Other & \\
\hline Wildfire Interactive & Advertising tools and platforms & \\
\hline WIMM Labs & Physical goods and services & Electronic devices and components \\
\hline Zagat & $\begin{array}{l}\text { Home, wellbeing and other personal } \\
\text { needs }\end{array}$ & \\
\hline Zave Networks & Physical goods and services & Retail \\
\hline Zetawire & Other & \\
\hline
\end{tabular}




\begin{tabular}{cc}
\hline Zynamics & Other \\
\hline Zync Render & Other \\
\hline
\end{tabular}

Source: authors based on Crunchbase data 